$[$ [rrI-r.o] ص ص

تأثير عدد من المتغيرات الاقتصادية في القيمة المضافة الزراعية

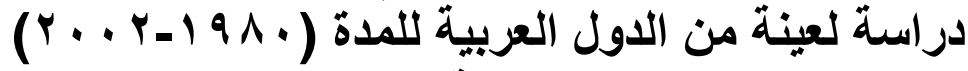
(مصر، سورية، الجزائر)

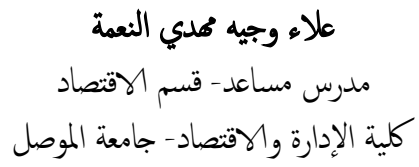

Alaawageeh@yahoo.com

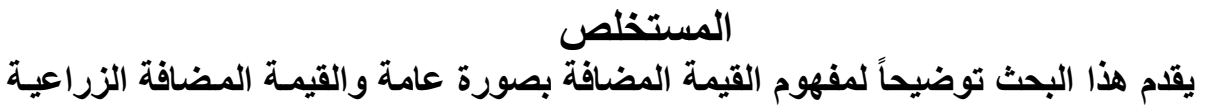

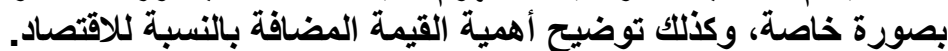

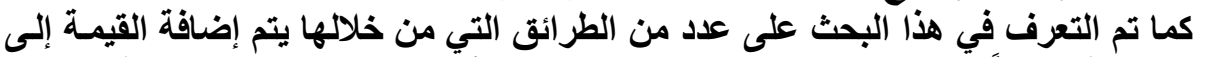

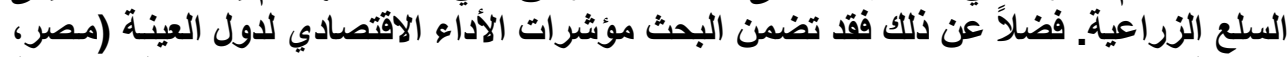

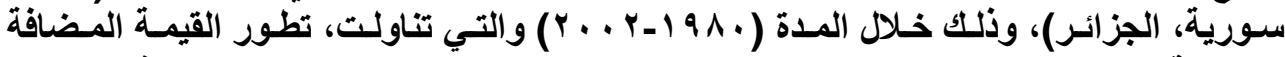

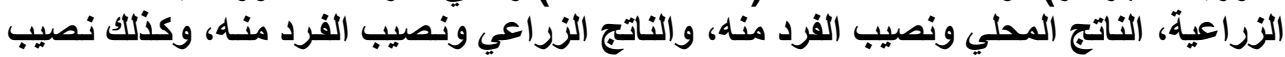

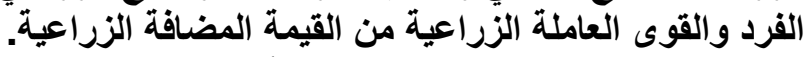

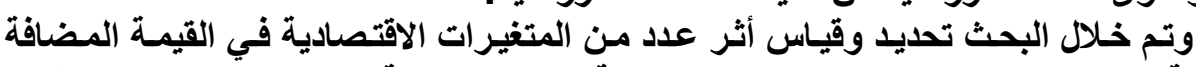

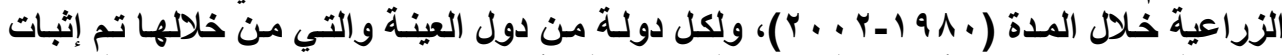

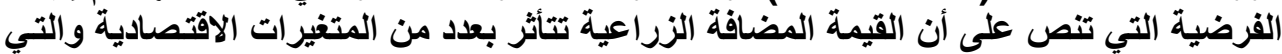

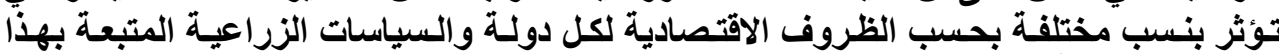
الخصوص، فضلاً عن دور وأهمية القطاع الزراعي في كل دولة. 


\title{
The Effect of Some Economic Variables in the Agricultural Value Added: A Sample of Arab Countries for Period 1980 - 2002 (Egypt, Syria and Algeria)
}

\author{
Alaa W. Al-Numa \\ Assistant Lecturer \\ Department of Business Administration \\ University of Mosul
}

\begin{abstract}
The present research demonstrates the concept of value added in general and agricultural value added in particular, and demonstrates the importance of value added with regard to economy.

Also, several techniques through which the value is added to the agricultural products were defined in this study. Moreover, the research includes the economic performance indicators of countries of sample, i.e. Egypt, Syria and Algeria, from 1980 to 2002. These indicators dealt with development of agricultural value added, local product and individual's share of such product, agricultural product and individual's share of such product as well as the individual and agricultural labors' shares of the agricultural value added.

In this research, many economic variables in the agricultural value added were determined and measured from 1980 to 2002 for each sample countries. Through these variables, the following hypothesis has been proved: The agricultural value added is affected by many economic variables and affects differently according to the economic conditions for each country and agricultural policies followed in this respect, in addition to the role and importance of agricultural sector in each country.
\end{abstract}

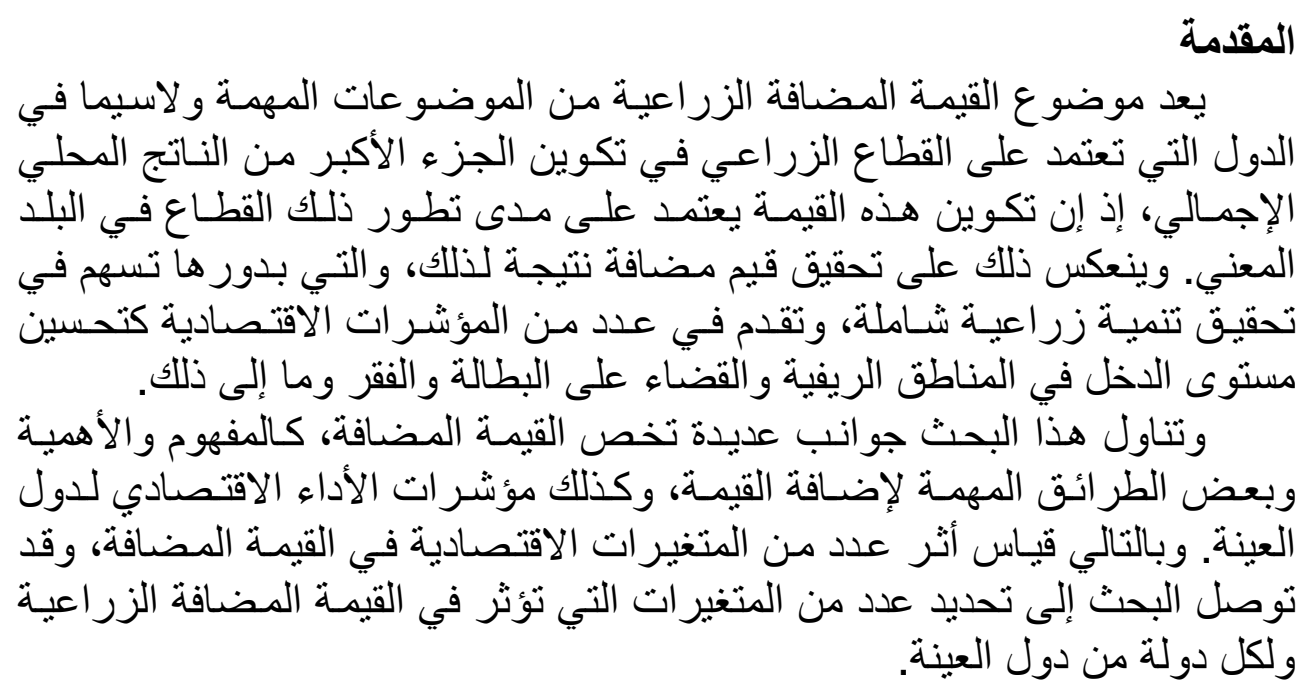




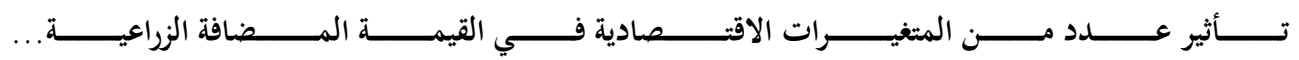

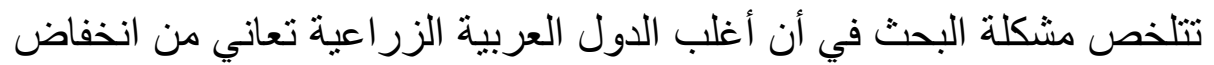

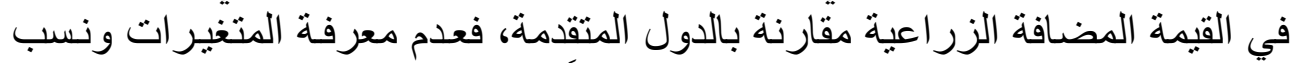

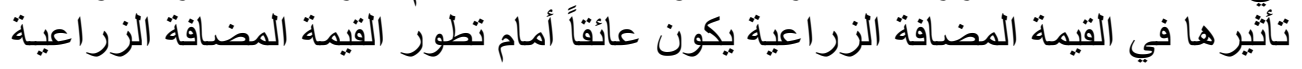
وتحسينها.

فرضية البحث

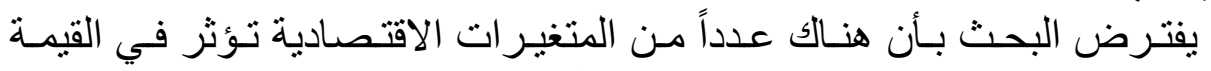

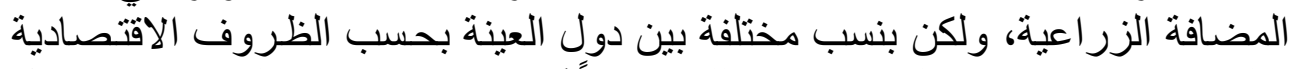

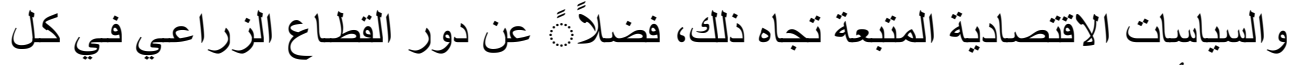
دولة وأهميته. - ماندان

هاف البحث

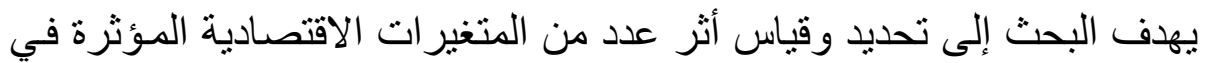

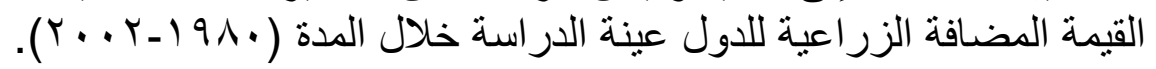

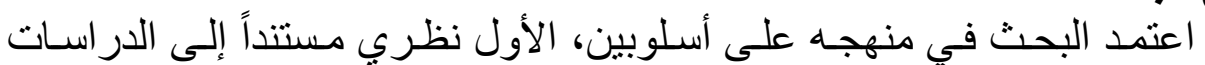

\section{منهج البحث}

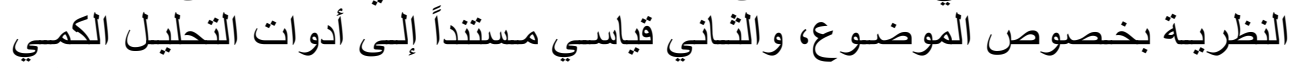

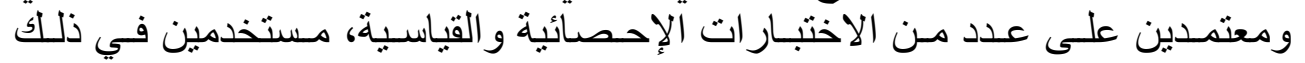

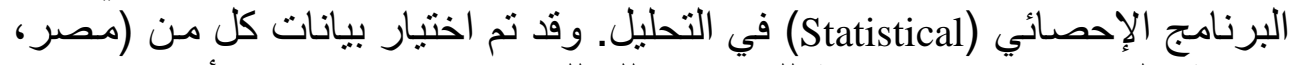

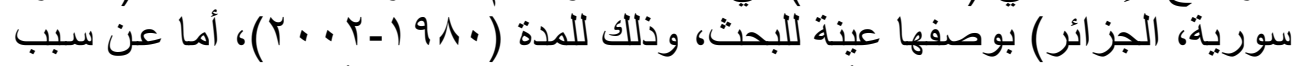

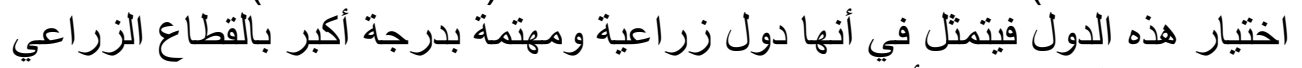

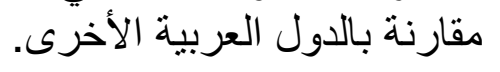

\section{مفهوم القيمة المضافة}

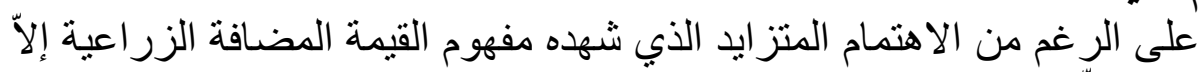

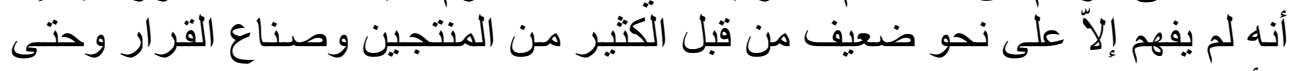

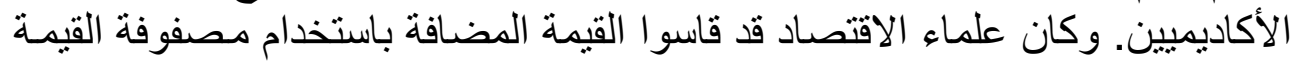

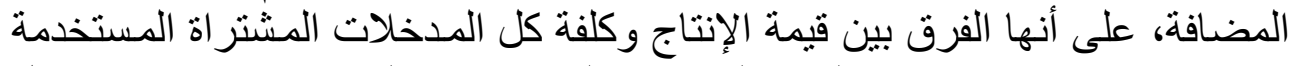

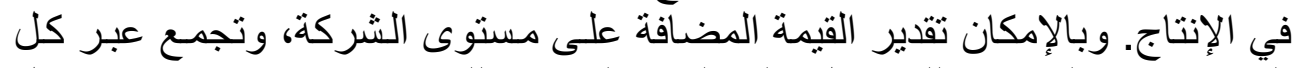

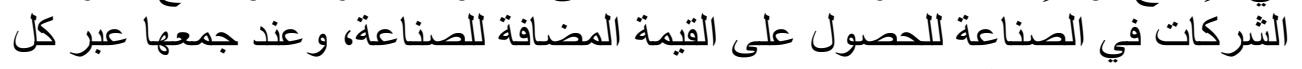

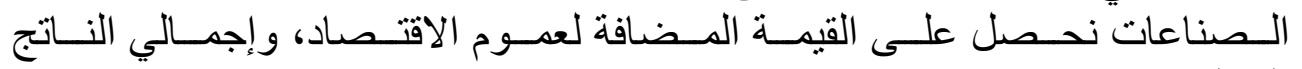

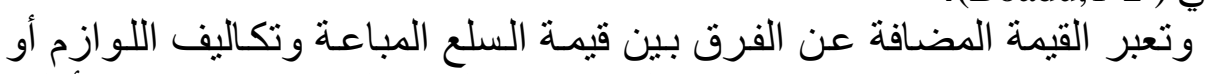

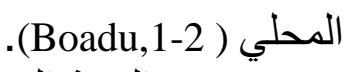

المو اد المستخدمة في إنتاجها، و هو مصطلح ينطبق على عملية تصنيع السلع الأولية 
الخام إلى سلع وسيطة و التي بعدئذ تعالج في المرحلة القادمة، مما يضيف قيمة سوقية منز ايدة في كل مرحلة (Cowan,2002,1) . ويشمل التعريف الواسع للقيمة المضافة (ما يضيف قيمة اقتيفة التصادية إلى المنتوج

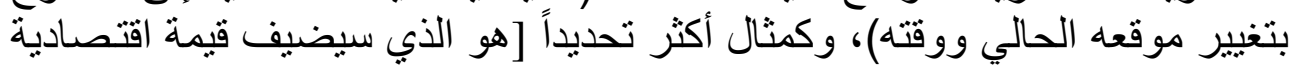

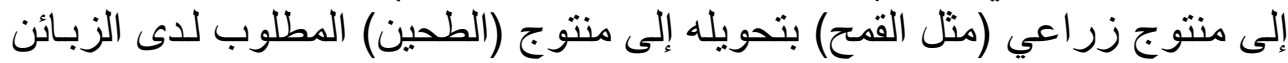
مثل (خبازو الخبز) (Coltrain,2000,5)]

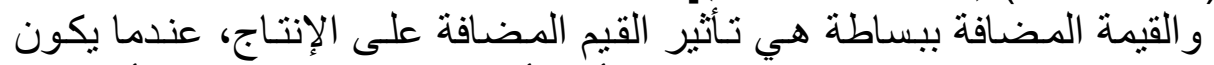

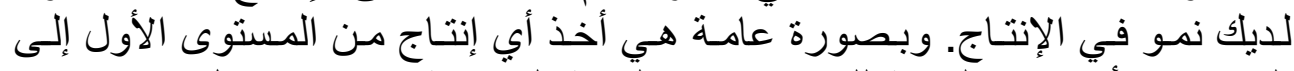

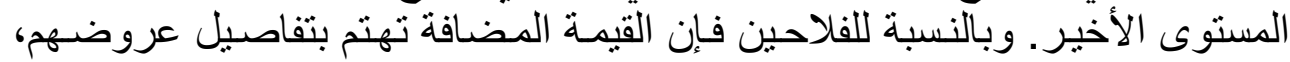
وتنقل الإستر اتيجية غير القابلة للربح إلى مشاريع رابحة (Fleming,2005,1) .

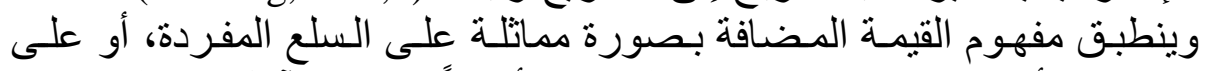

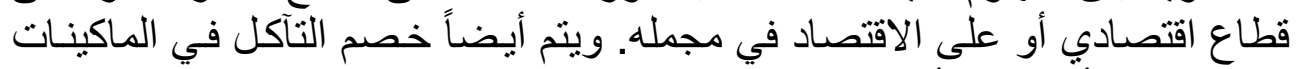

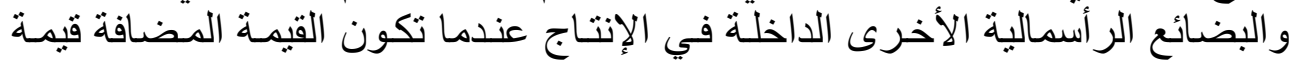

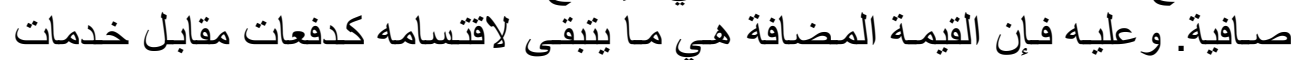

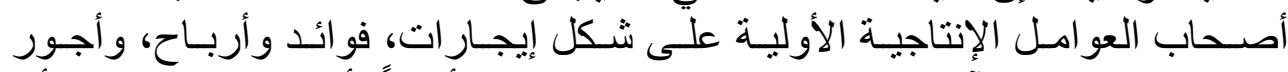

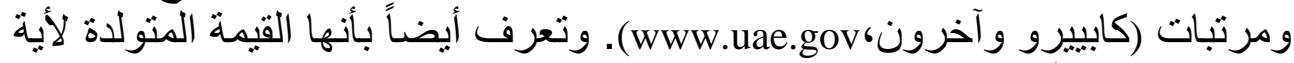

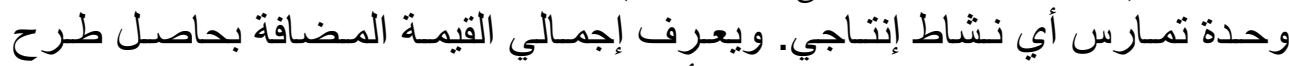

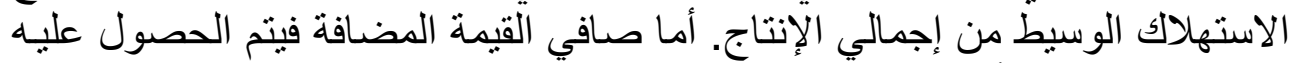

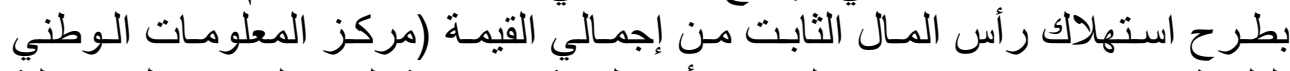

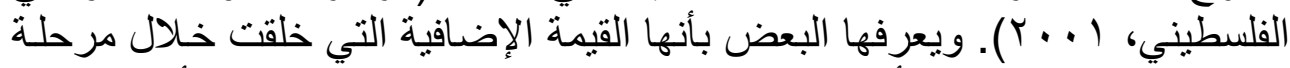

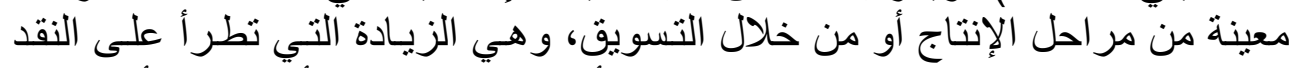

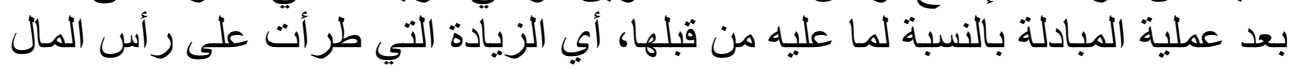

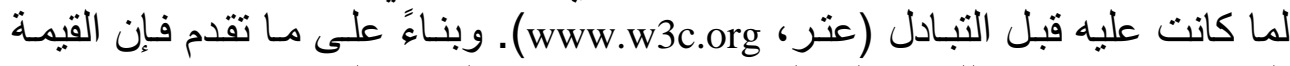
المضافة هي مقياس للثروة المتولدة عن جهود وذكاء الجنس البشري (Boadu, 2).

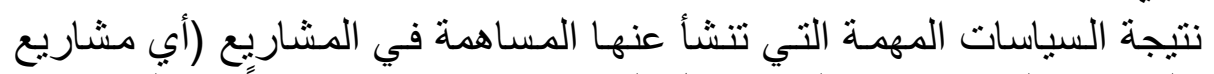

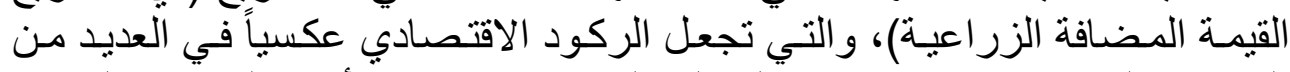

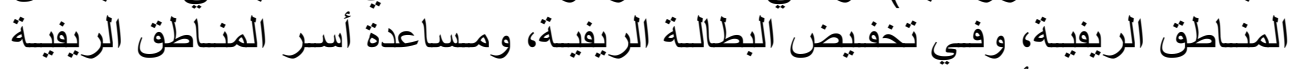

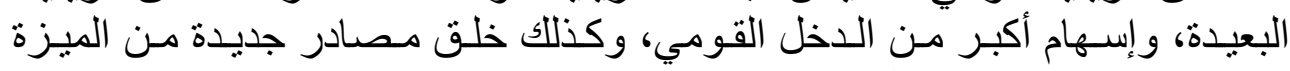

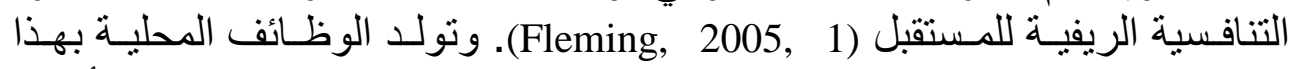

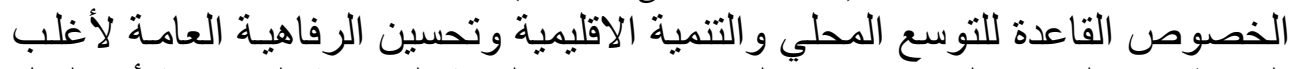

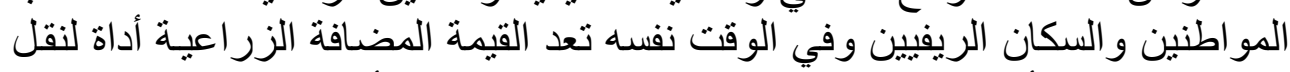

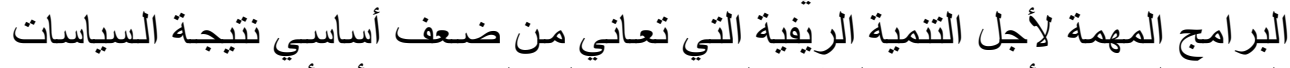

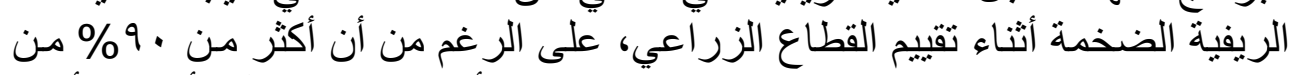

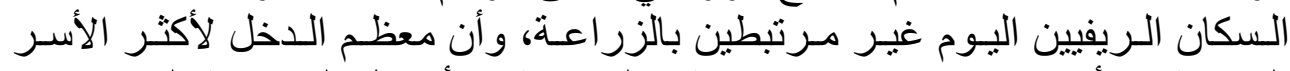

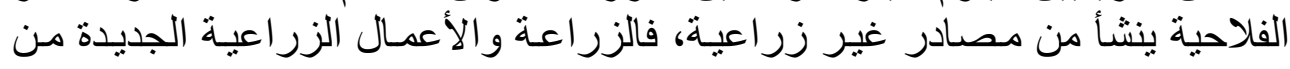




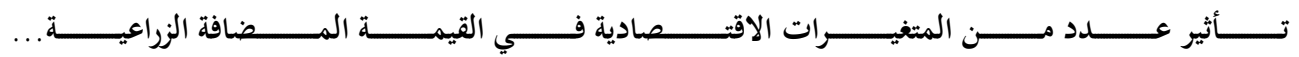

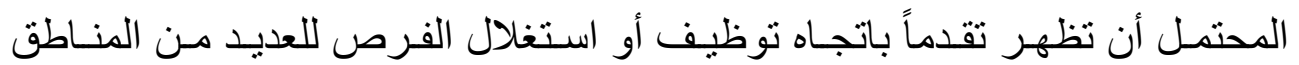

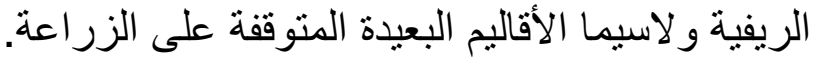

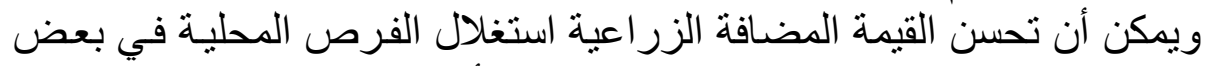

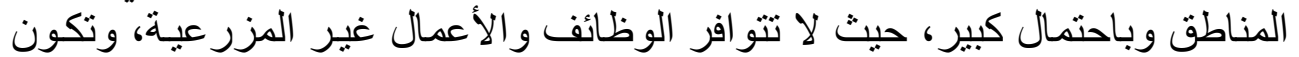

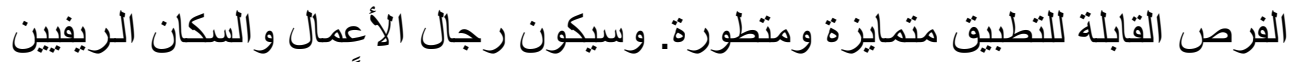

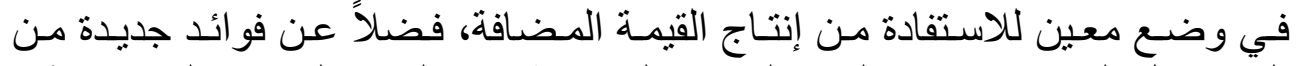

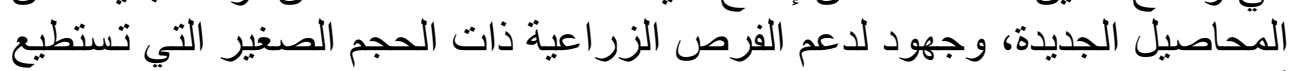

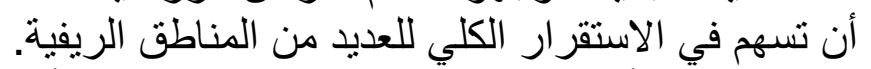

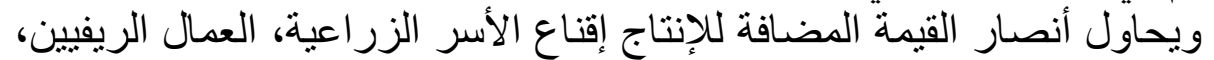

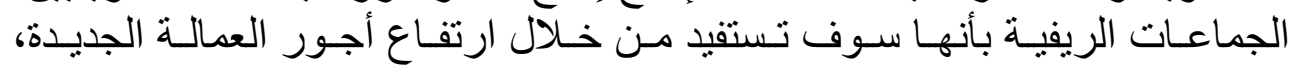

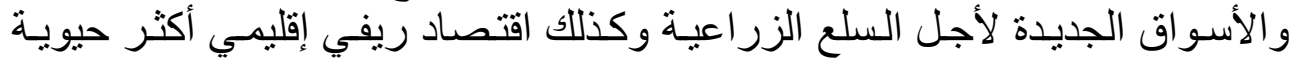
.(Cowan,2002,1,41)

\section{طرائق إضافة القيمة}

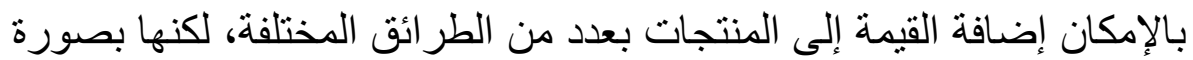

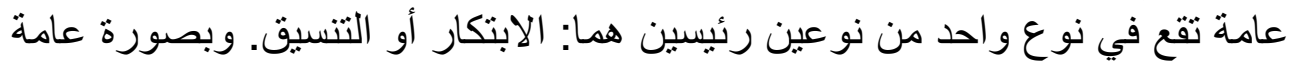

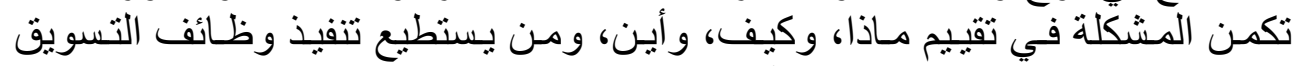

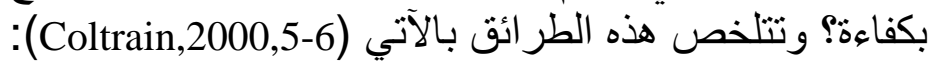

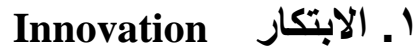

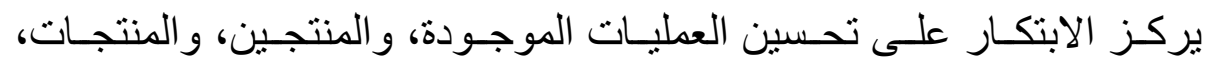

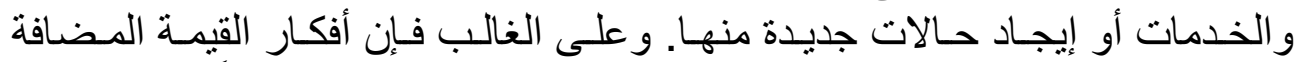

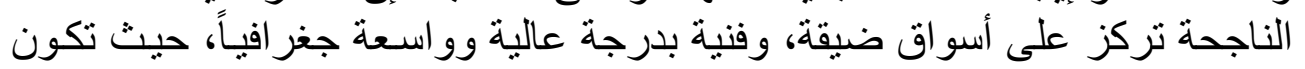

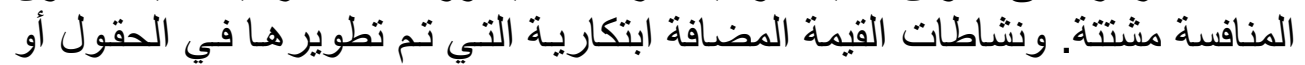

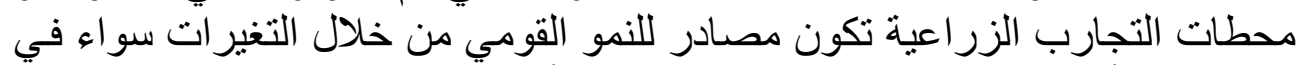
نوع المنتج أو في تكنولوجيا إنتاجية. وبتشجيع الأفكار الابنكارية تصبح إضافية القية القيمة حقيقة و اقعية.

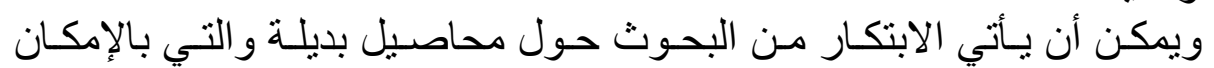

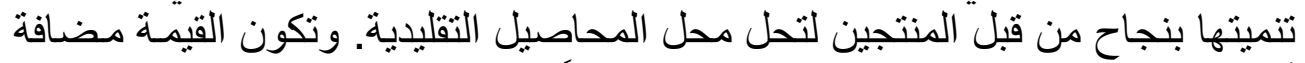

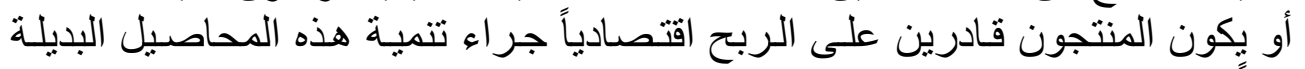
بدلاً من المحاصيل التقليدية.

Industrial Innovation الابتكار الصناعي 
هناك نوع محدد من الابنكار الصناعي يعالج المحاصيل التقليدية، ويحولها إلى ثلى

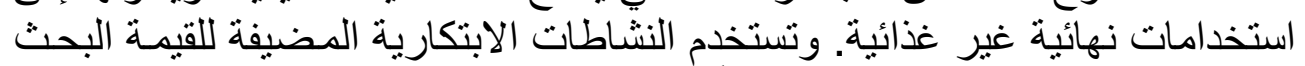

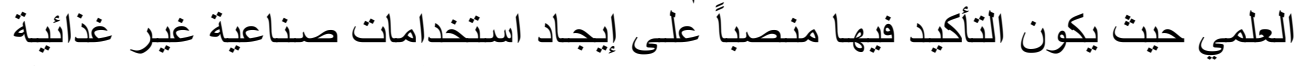

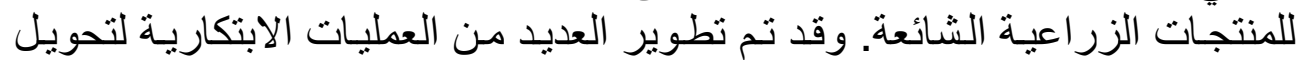

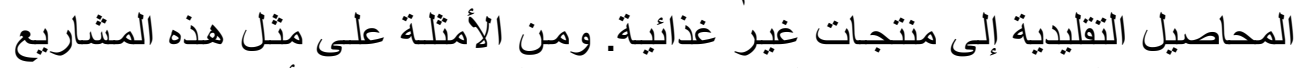

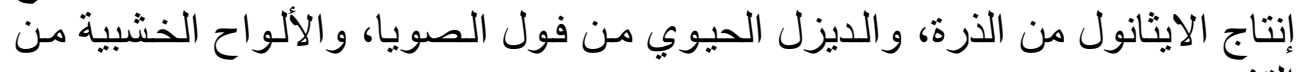

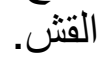

\section{r. ب. التنسيق Coordination}

يركز التنسيق على الترتيب بين أولنأك الذين ينتجون ويسوقون منتجات الحقل.

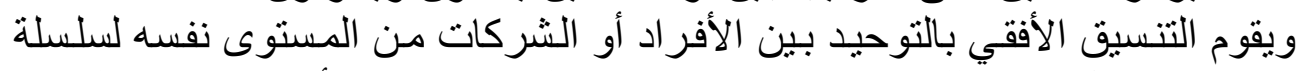

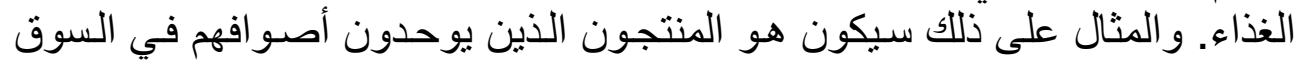
لتكون حمل شاحنة.

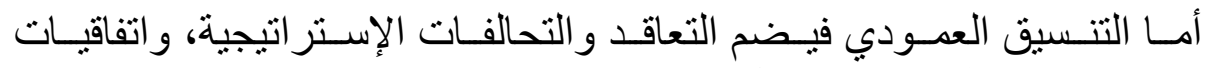

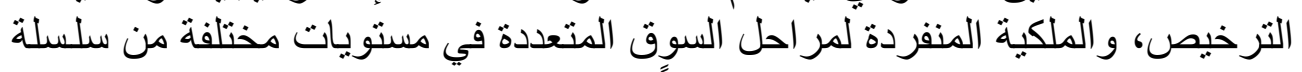

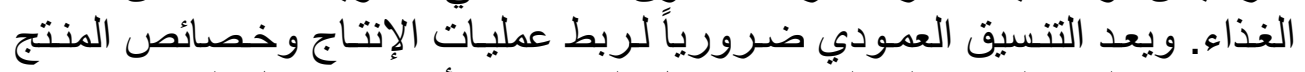

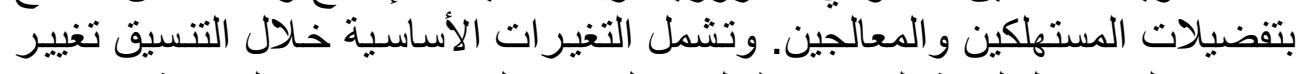

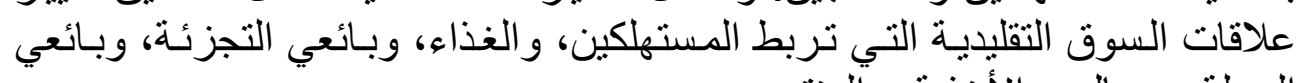
الجملة، ومعالجي الأغذية، وآلكنتجين.

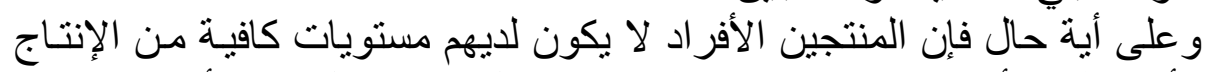

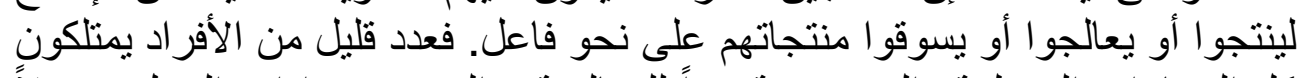

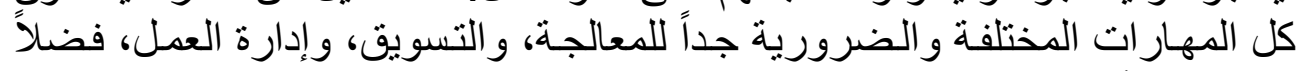

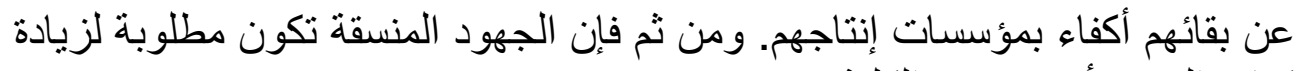
كفاءة السوق أو تخفيض الكلفة.

عertical Integration ـ التكامل العمودي

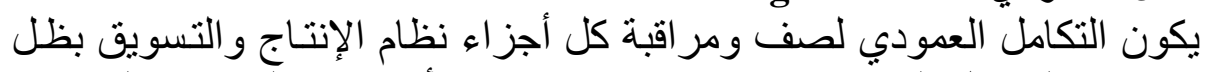

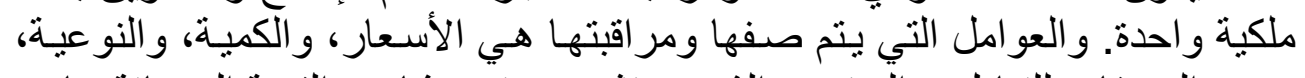

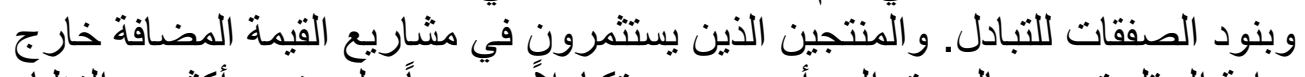

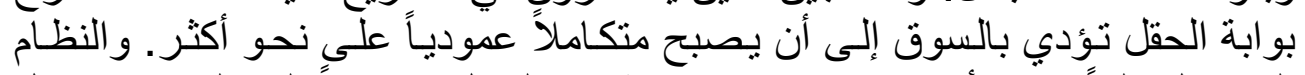

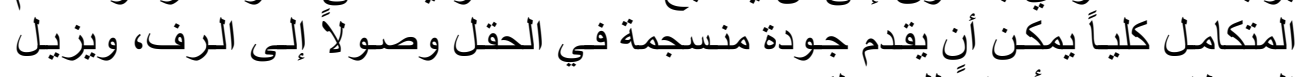
الوسطاء ويدخر أمو الاً للمستهلكين.

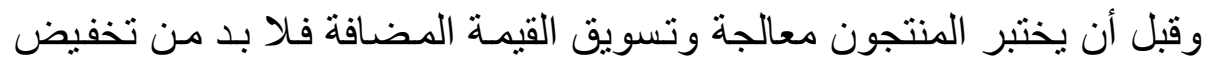

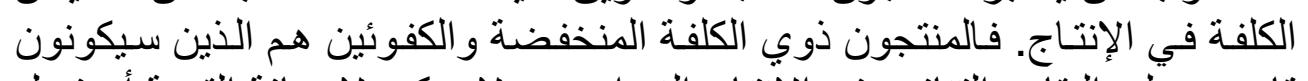

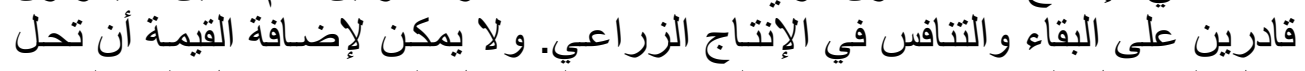

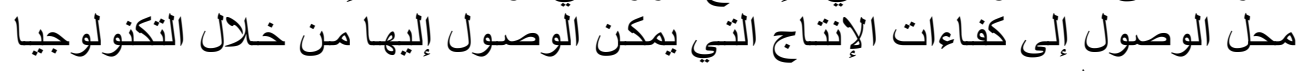




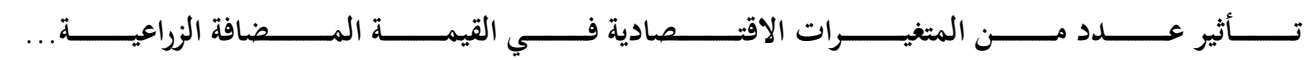

مؤشرات الأداء الاقتصادي لدول العينة

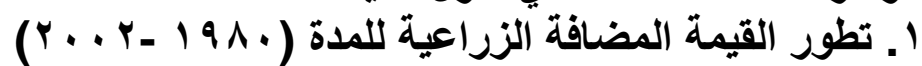

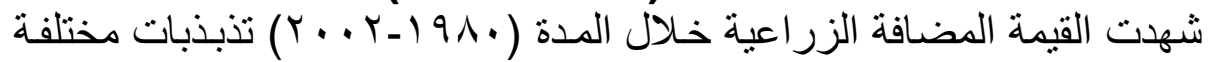

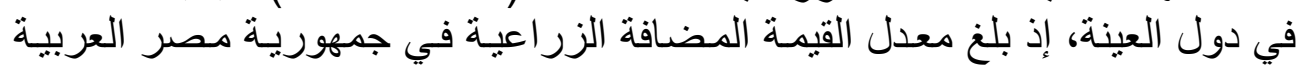

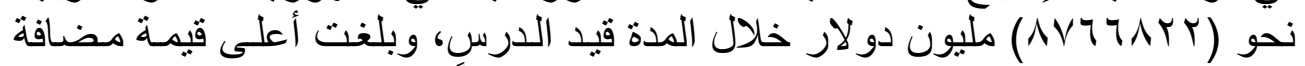

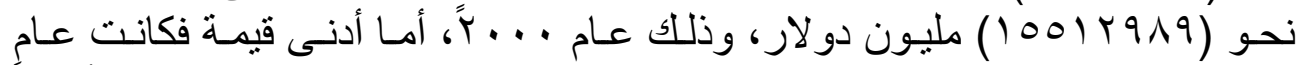

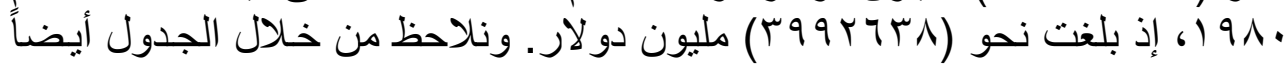

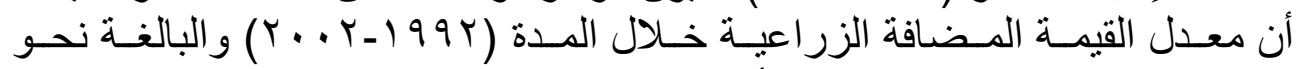

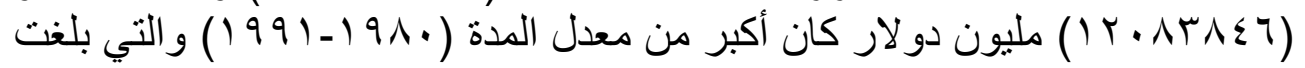

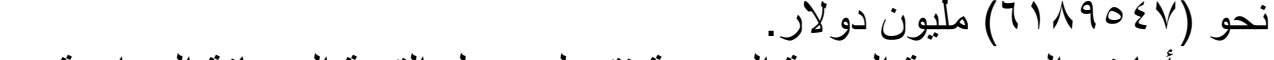

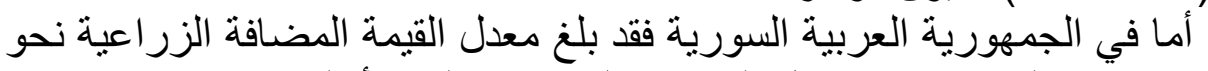

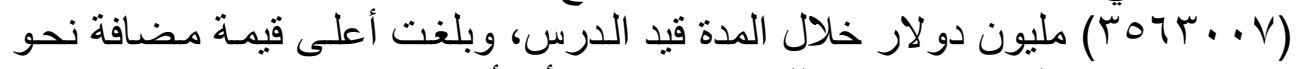

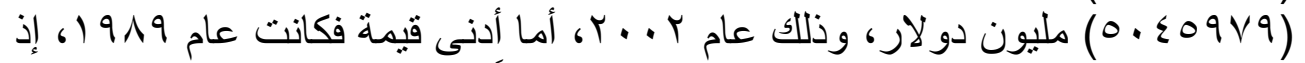

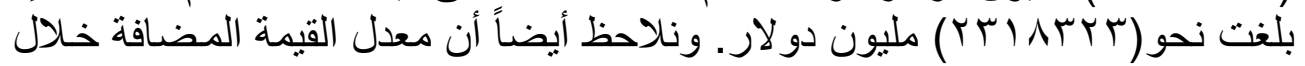

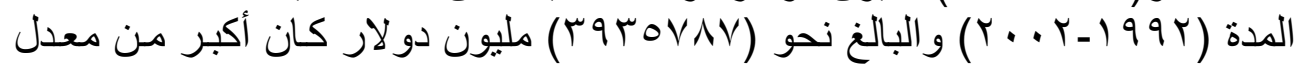

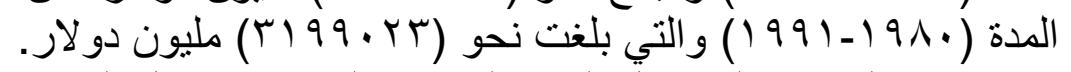

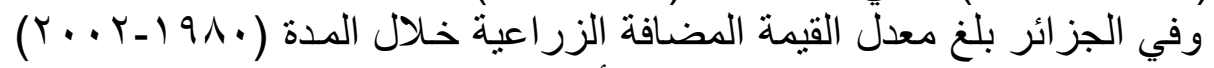

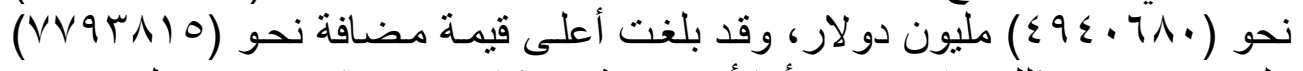

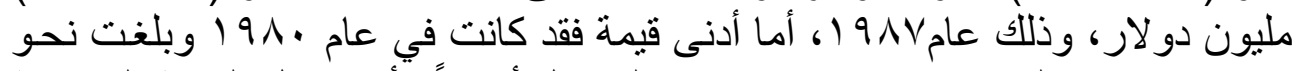

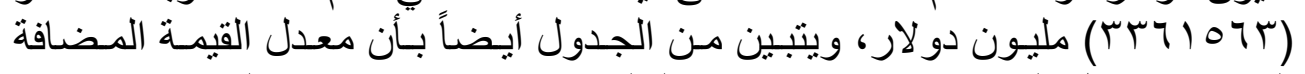

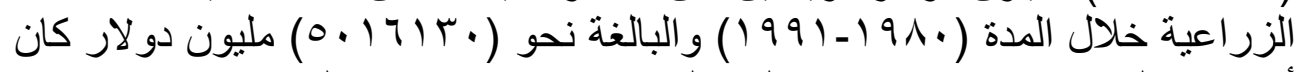

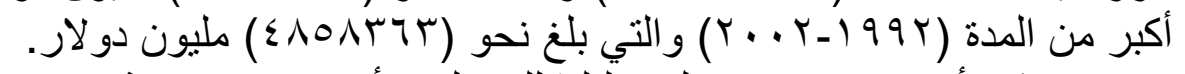

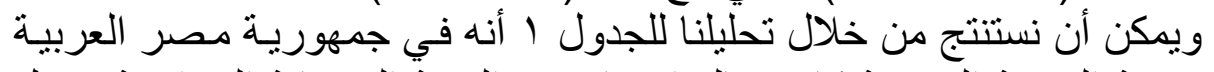

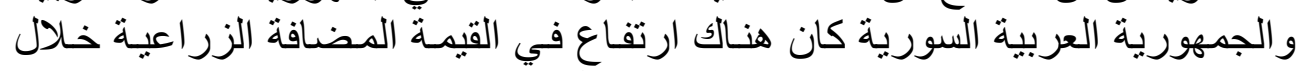

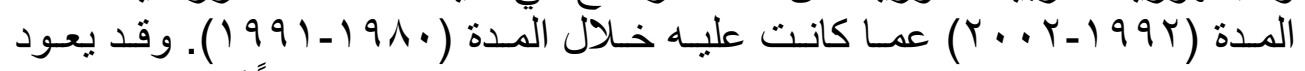

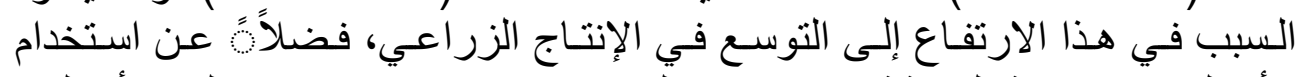

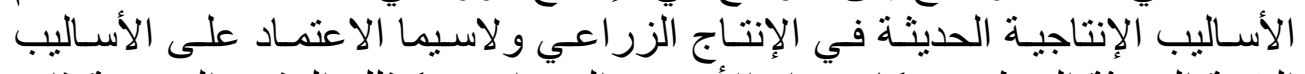

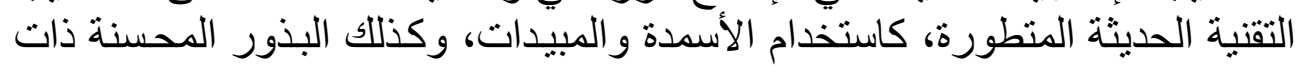

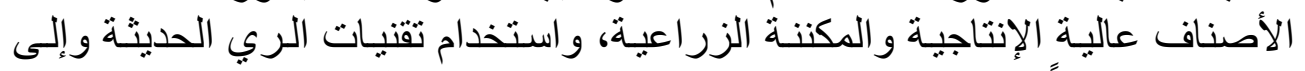

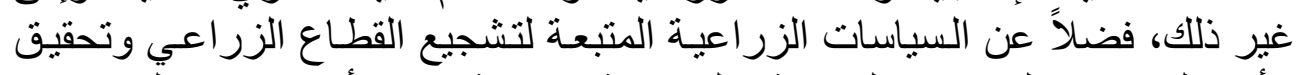

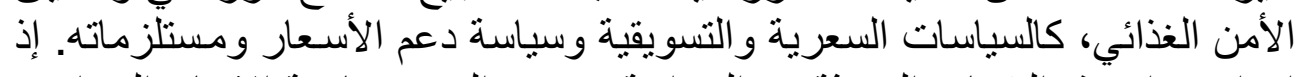

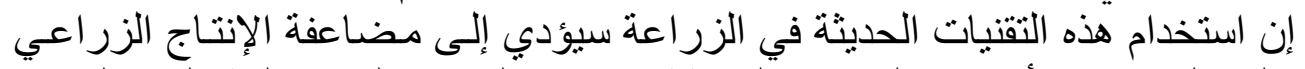

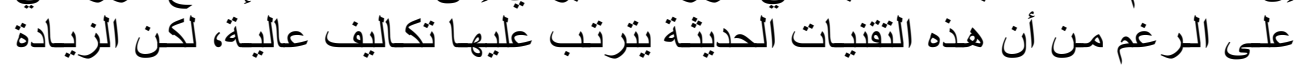




\section{النعمة [Y,}

الحاصلة في الإنتاج سوف تغطي هذه التكاليف وتزيد، مما يؤثر على القيمة المضافة

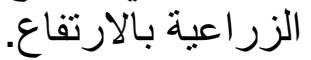

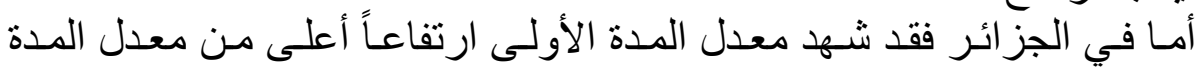

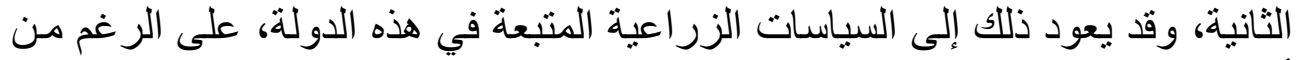

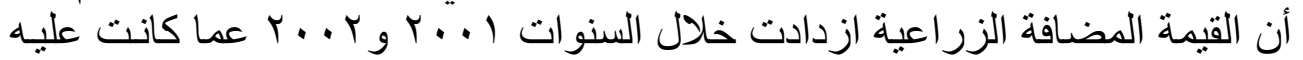

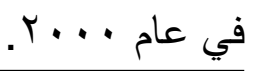

\section{الجدول 1}

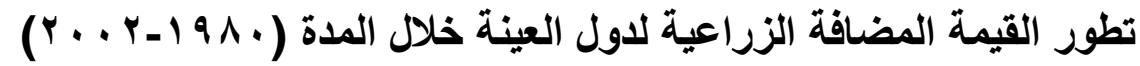
(دولار)

\begin{tabular}{|c|c|c|c|}
\hline الجزائر & سورية & مصر & السنة \\
\hline $3,361,563,000$ & $2,620,480,512$ & $3,992,638,976$ & 191. \\
\hline $3,776,820,000$ & $2,985,847,808$ & $4,494,594,560$ & 1911 \\
\hline $3,505,945,000$ & $3,256,156,672$ & $4,842,364,416$ & 1914 \\
\hline $3,466,422,000$ & $3,720,117,504$ & $5,313,155,072$ & 1914 \\
\hline $3,672,192,000$ & $3,411,688,704$ & $5,906,256,896$ & $191 \varepsilon$ \\
\hline $4,793,349,000$ & $3,414,179,328$ & $6,686,211,072$ & 1910 \\
\hline $5,912,378,000$ & $3,142,485,504$ & $7,044,901,888$ & 1917 \\
\hline $7,793,815,000$ & $2,864,760,064$ & $7,943,654,976$ & $191 \mathrm{~V}$ \\
\hline $6,576,723,000$ & $3,190,434,304$ & $6,312,322,560$ & 1911 \\
\hline $6,676,304,000$ & $2,318,323,456$ & $7,432,362,496$ & 1919 \\
\hline $6,441,170,000$ & $3,481,513,984$ & $7,956,483,560$ & 199. \\
\hline $4,216,965,000$ & $3,982,291,712$ & $6,350,947,328$ & 1991 \\
\hline $5,376,442,000$ & $4,203,031,296$ & $6,523,557,376$ & 1994 \\
\hline $5,594,345,000$ & $3,972,989,184$ & $7,331,032,576$ & 1994 \\
\hline $3,927,665,000$ & $2,818,080,000$ & $8,155,397,632$ & 1995 \\
\hline $3,986,321,000$ & $3,214,051,840$ & $9,451,489,280$ & 1990 \\
\hline $5,074,065,000$ & $3,822,095,872$ & $10,898,584,576$ & 1997 \\
\hline $4,519,383,000$ & $3,738,560,256$ & $12,354,572,288$ & $199 V$ \\
\hline $5,267,373,000$ & $4,466,980,864$ & $13,335,890,944$ & 1991 \\
\hline $5,053,024,000$ & $3,812,848,896$ & $14,430,845,952$ & 1999 \\
\hline $4,411,374,000$ & $4,088,013,312$ & $15,512,989,696$ & $r \ldots$ \\
\hline $5,015,865,000$ & $4,378,262,016$ & $15,476,592,640$ & $r \cdot l_{1}$ \\
\hline $5,216,138,000$ & $5,045,979,136$ & $13,891,064,832$ & $r . . r$ \\
\hline
\end{tabular}

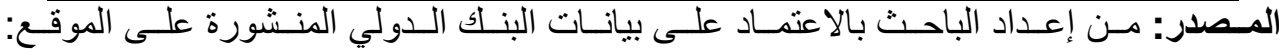




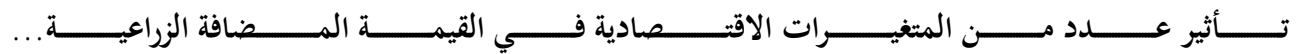

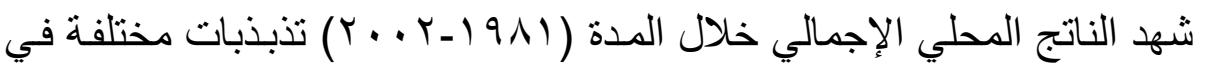

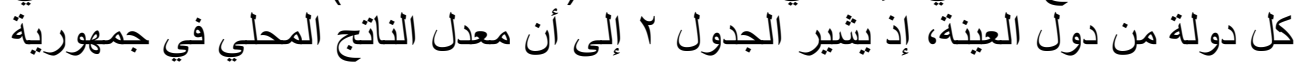

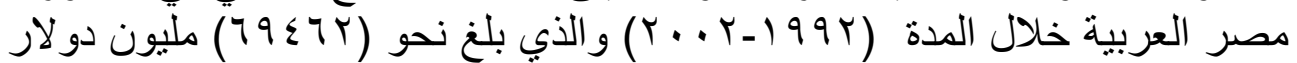

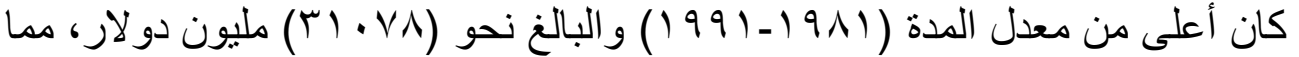

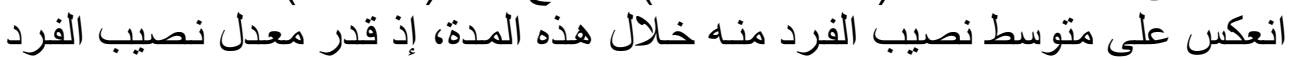

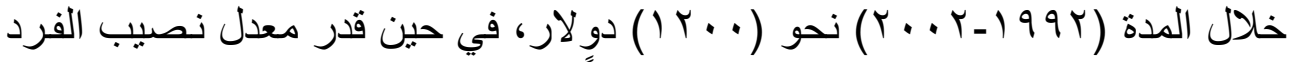

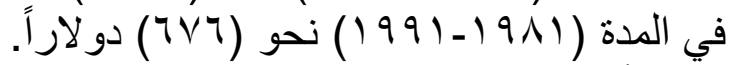

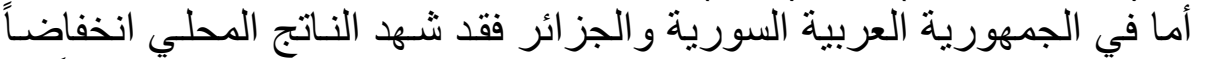

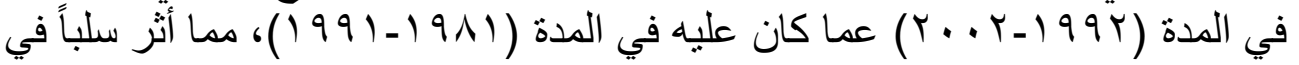

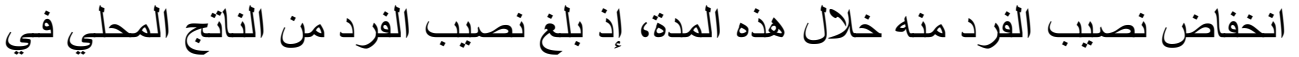

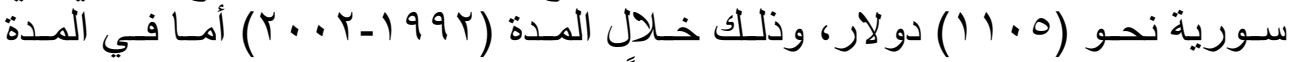

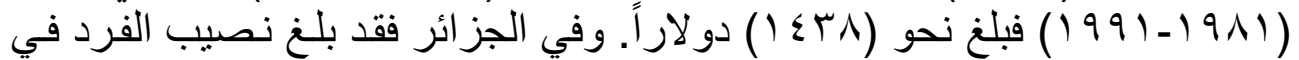

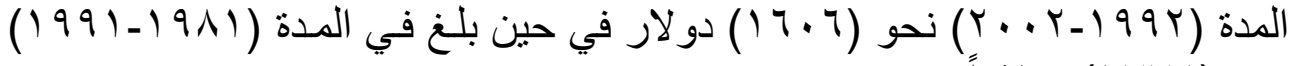

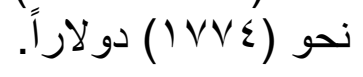

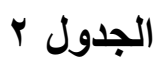 \\ الناتج المحلي الإجمالي ونصيب الفرد منه}

\begin{tabular}{|c|c|c|c|c|c|c|}
\hline \multicolumn{3}{|c|}{ نصيب الفرد من الناتج المحلي (دولار) } & \multicolumn{4}{|c|}{ الناتج المحلي الإجمالي (مليون دولار) } \\
\hline$r \ldots r$ & 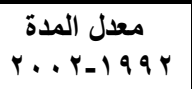 & 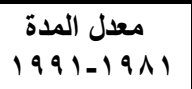 & $r \ldots r$ & 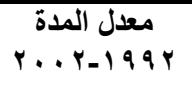 & | معدل المدة | | | | | & \\
\hline $1 \% 10$ & 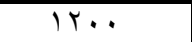 & $T V 7$ & Nov1. & $79 \leqslant 7 \%$ & $\mu 1 \cdot V \lambda$ & مصر \\
\hline TY.T & 11.0 & $1 \leqslant \mu \Lambda$ & r.779 & $17 V \varepsilon$. & $\overline{M A N T}$ & سورية \\
\hline TATE & 17.7 & $T V V \varepsilon$ & $079 \xi 1$ & $\sum 700 Y$ & $\sum 1091$ & الجزائر \\
\hline
\end{tabular}

r. الناتج الزراعي ونصيب الفرد منه إنه

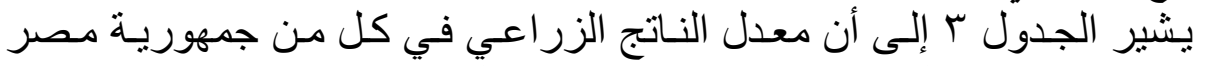

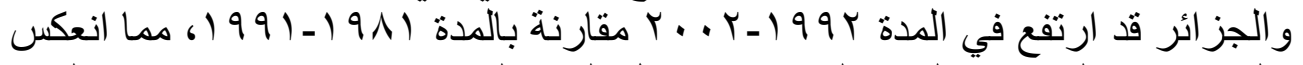

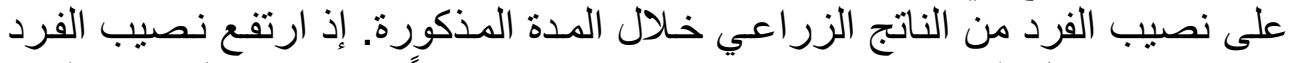

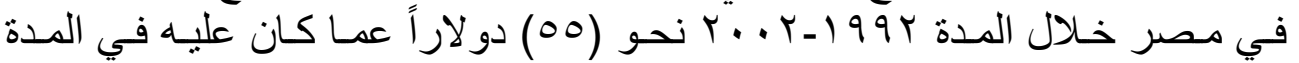

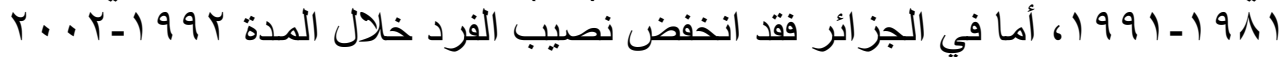

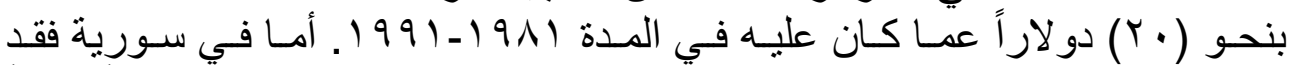

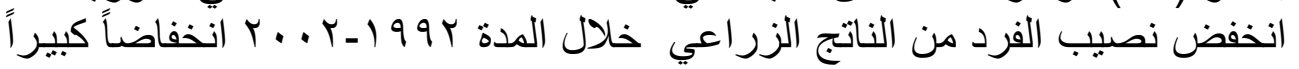




\section{النعمة [؛ [}

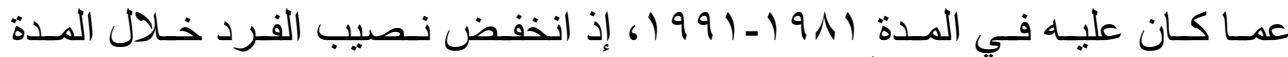

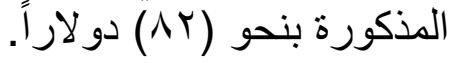

\begin{tabular}{|c|c|c|c|c|c|c|}
\hline \multicolumn{7}{|c|}{ الجدول اعى ونصيب الفرد منه } \\
\hline \multicolumn{3}{|c|}{ نصيب الفرد من الناتج الزراعي (دولار) } & \multicolumn{4}{|c|}{ الناتج الززراعي (مليون دولار) } \\
\hline$r+r^{\prime}$ & 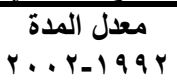 & 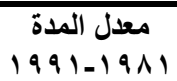 & Y.P & 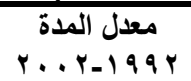 & | معدل المداة & \\
\hline 191 & 110 & $1 \mu$ & TRY. & $1.91 \mathrm{~V}$ & voq. & مصر \\
\hline$r \cdot r$ & rq9 & $r \wedge 1$ & $019 V$ & $\{0 . r$ & 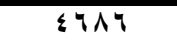 & سورية \\
\hline 171 & TV. & 19. & OrYT & $\xi q q^{2}$ & $\varepsilon 7 . V$ & الجزائر \\
\hline
\end{tabular}

المصدر: من إعداد الباحث بالاعتمـاد على قاعدة بيانـات المنظمة العربية للتنمية الزر اعية على المى

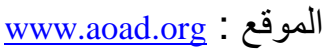

ع. نصيب الفرد ونصيب القوى العاملة الزراعية من القيمة المضافة الزراعية

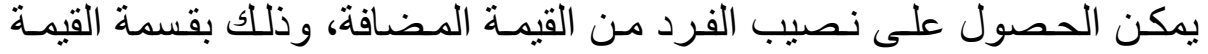

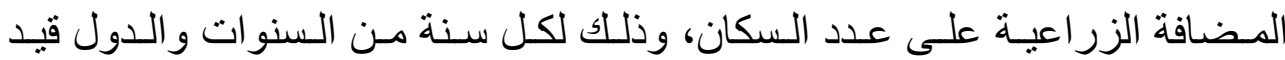

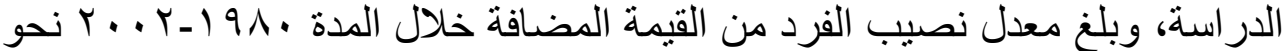

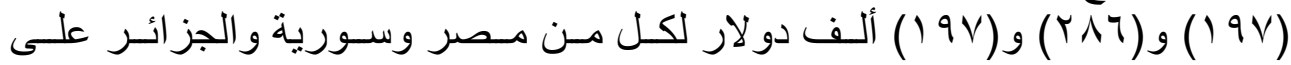

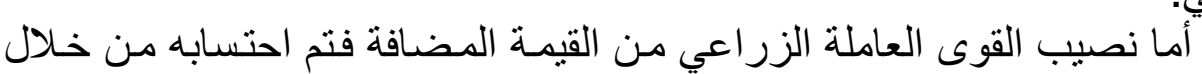

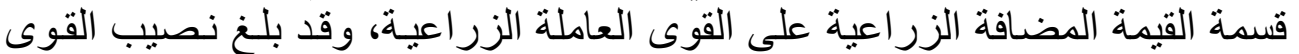

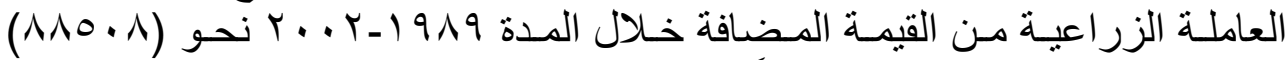

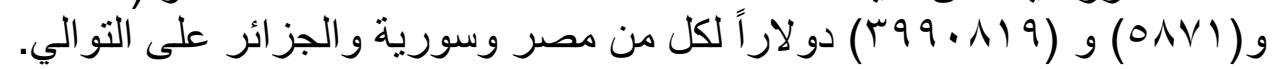

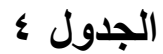

نصيب الفرد ونصيب القوى العاملة الزراعية من القيمة المضافة الزراعية

\begin{tabular}{|c|c|c|}
\hline نصيب القوى العاملة الزراعية من القيمة & \multicolumn{2}{|c|}{ نصيب الفرد من القيمة المضافة الزراعية } \\
\hline Pعدل المدة & 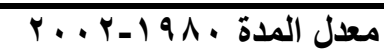 & \\
\hline$\Lambda \wedge 0 \cdot \Lambda \cdot r$ & $19 V . Y \wedge 99$ & مصر \\
\hline $0 \wedge V 1.7 Y 1$ & YAT.YTYY & سورية \\
\hline 499.119 & $19 V . Y \wedge 99$ & الجزائر \\
\hline
\end{tabular}

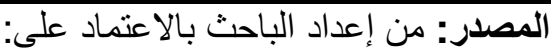

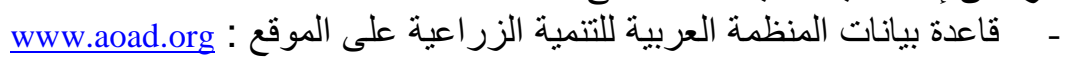

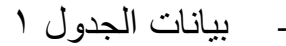




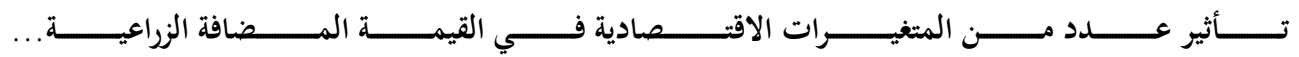

سوف نحساول من خـلال هذا البحث أن نوضـح المتغير ات المستقلة والمعتمدة المستخدمة في الدر استة وكما يأتي:

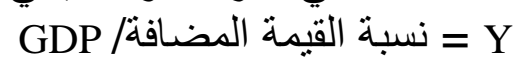

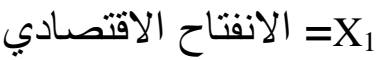

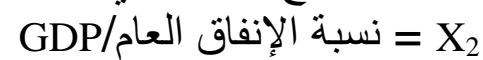
معدل التضخ النفاف = X

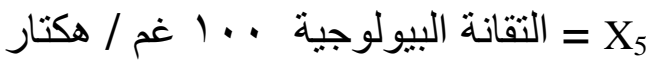

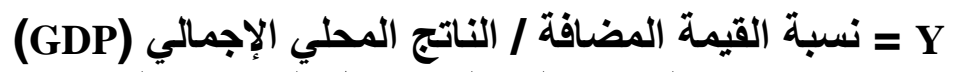

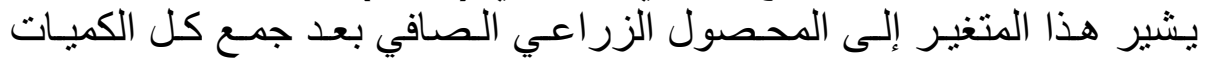

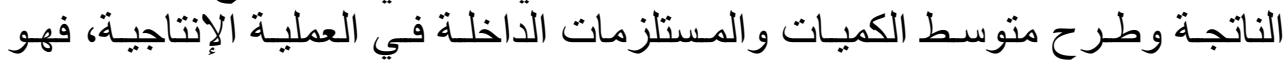

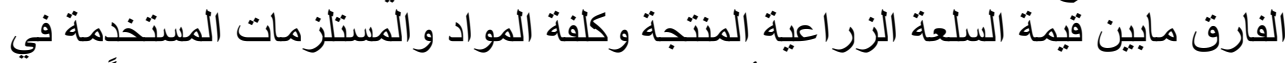

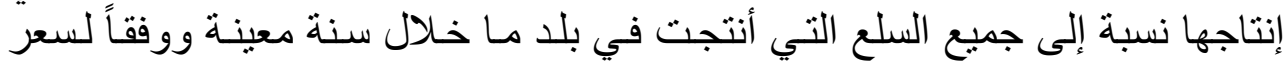

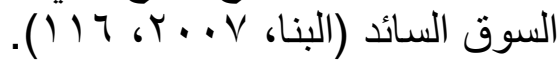

$$
\text { X1 }
$$

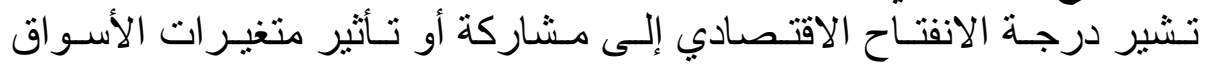

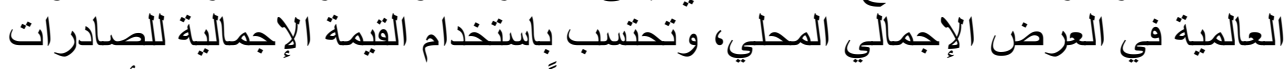

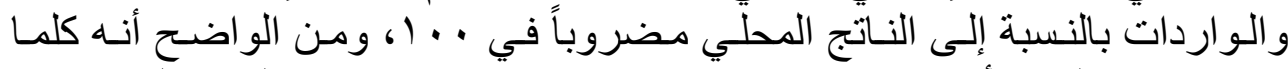

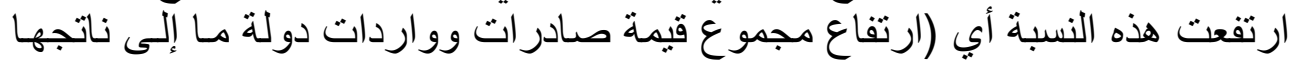

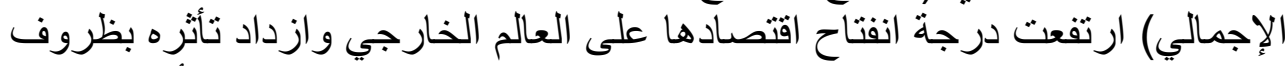

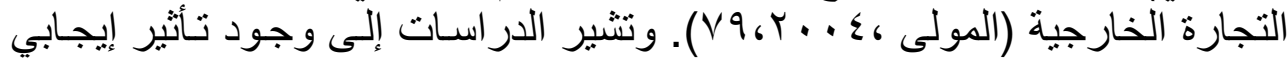

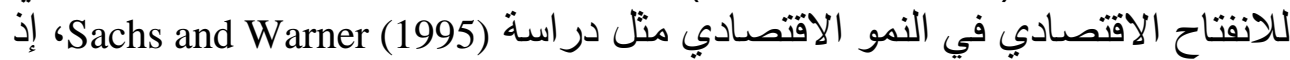

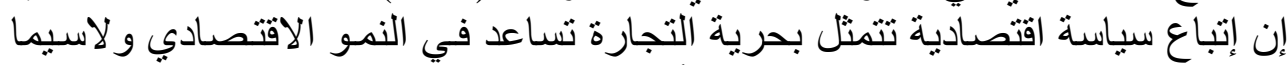

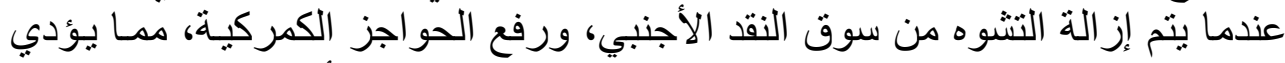

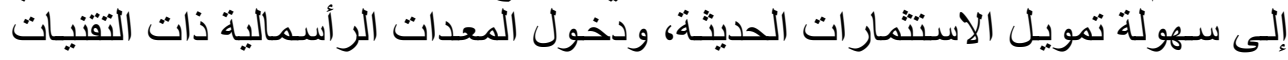

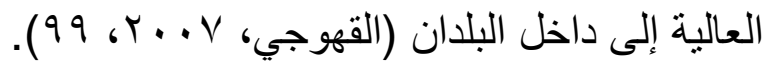

ن2=X2 نسبة الإفاق العام / الناتج المحلي الإجمالي (GDP) (تلخل الداولية)

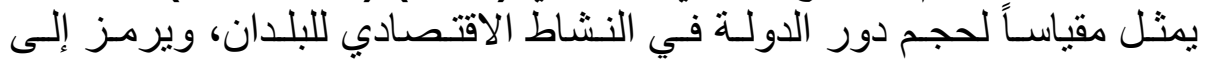

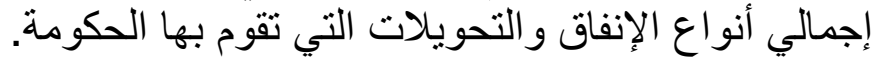

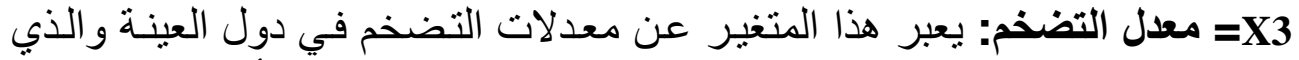

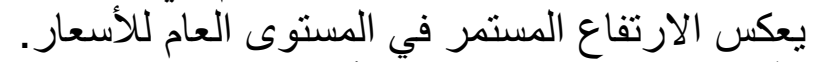

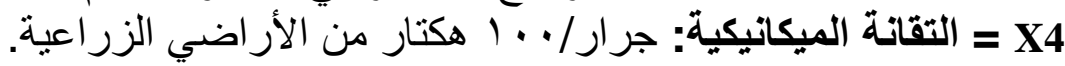




\section{النعمة [Y1)}

تتمثل هذه التقانـة في استخدام الآلات و المعدات الزر اعيـة الحديثة كالساحبات

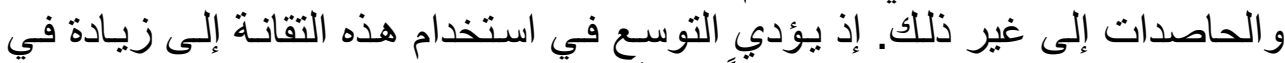

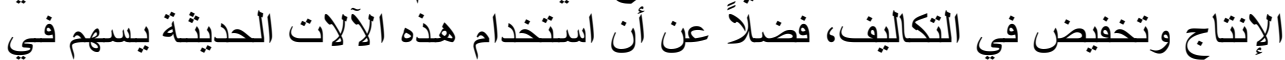

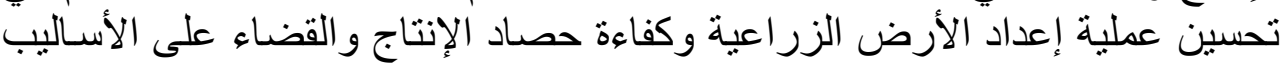

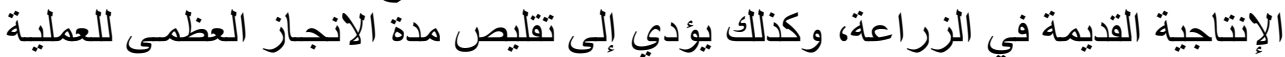

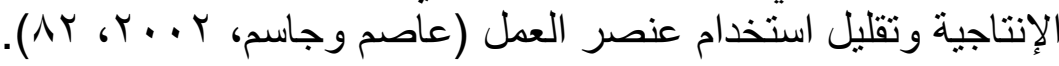

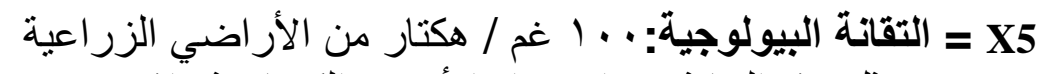

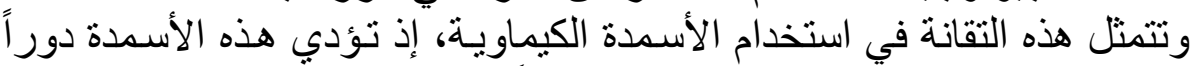

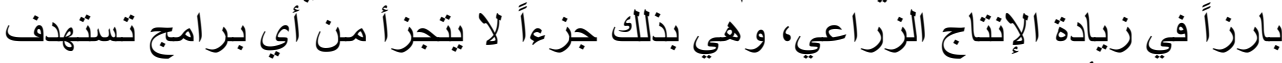

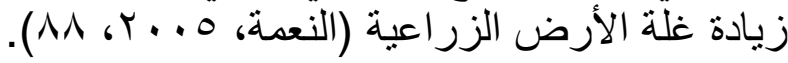

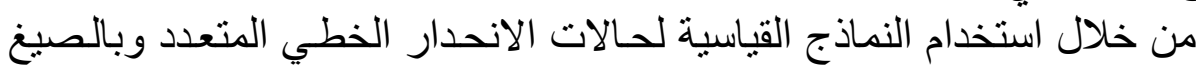

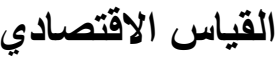

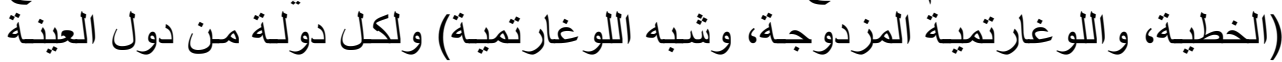

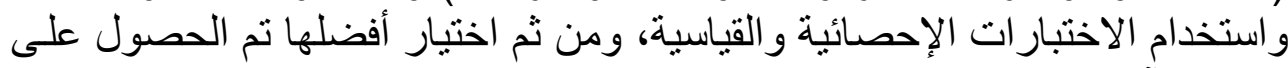

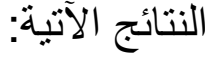

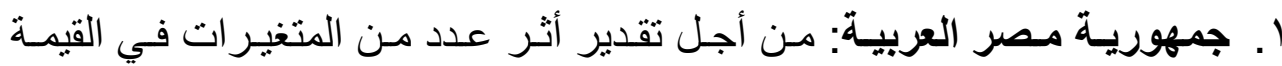

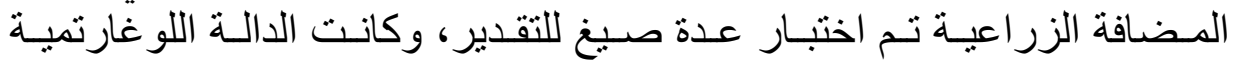
المزدوجة قد أعطت أفضل النتائج الآتية:

$\log Y=-2.76917-0.04886$ LOG X1+ 0.12482 LOG X2 + 0.20296 LOG X3

$\mathrm{t}^{*} \quad 0.8$

-0.16644 LOG X4 + 0.24160 LOG X5

$\mathrm{R}^{2}=86 \%$

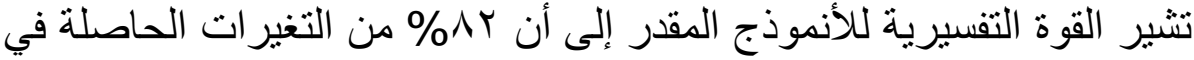

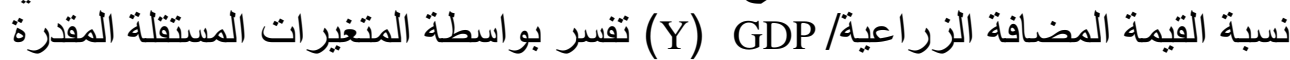

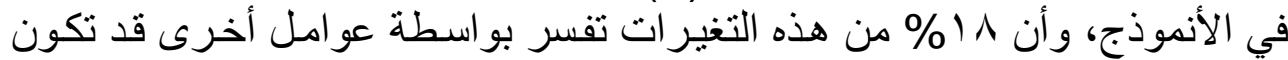

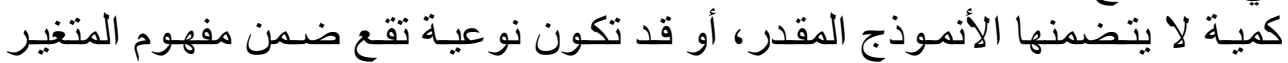

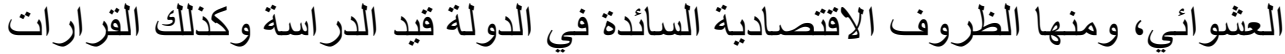

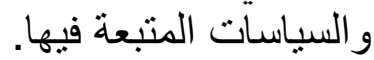




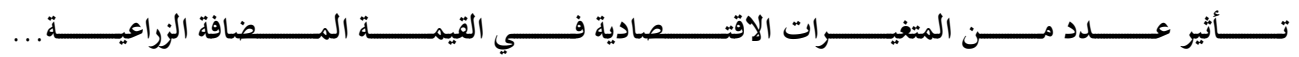

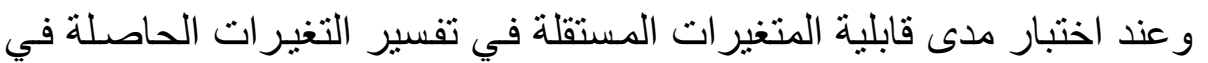

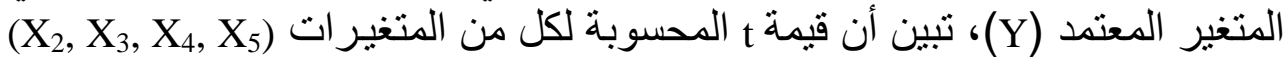

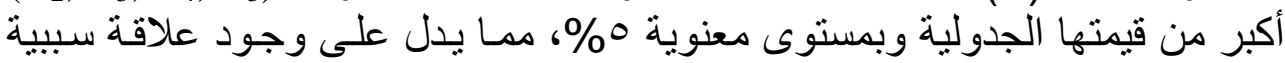

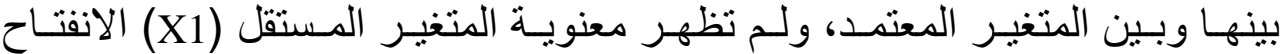

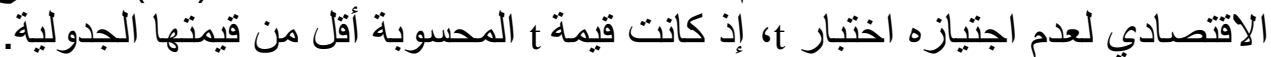

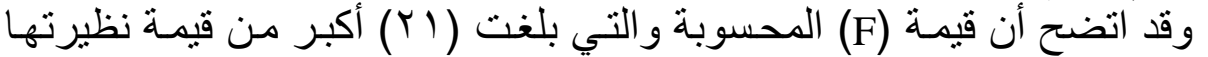

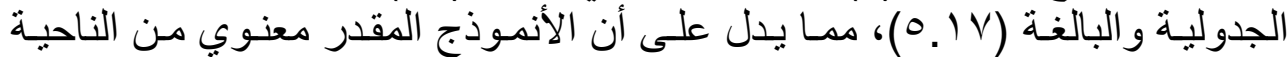

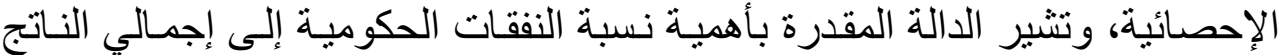

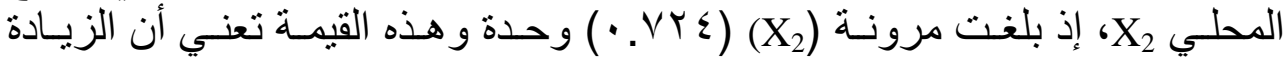

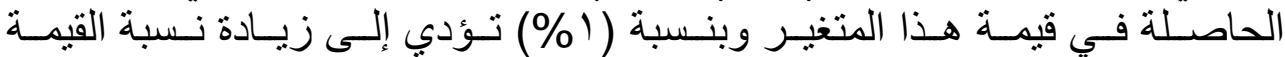

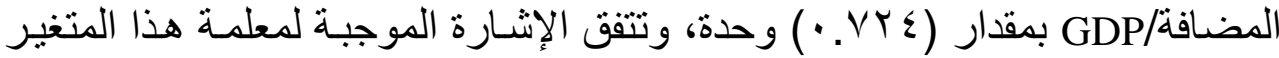
مع منطق النظرية الاقتصادية و الدراسات النات السابقة.

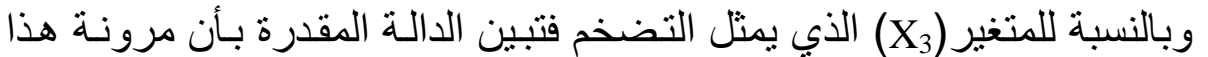

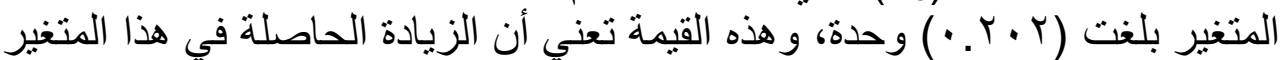

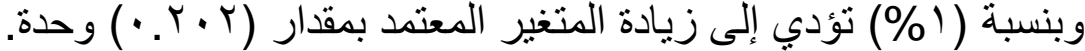

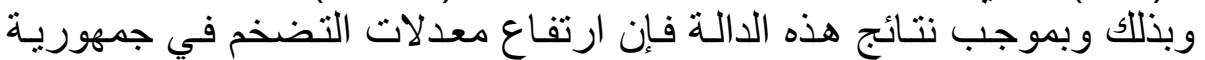

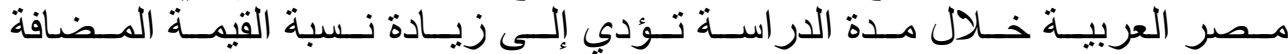
الزر اعية/GDP، وبعبارة أخرى فإن جزءاً من هذه القيمة يمكن أن تتحقق عن طريق وجاءت نتيجة المتغير المستقل (X) و الذي يمثل التقانـة الميكانيكية سـالبة، إذ إذية

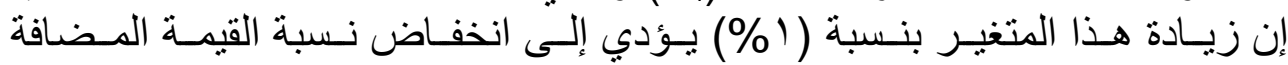

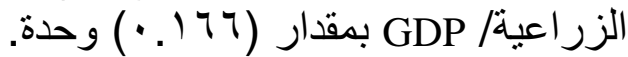

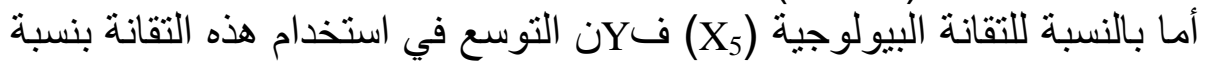

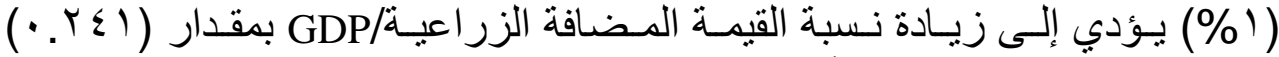

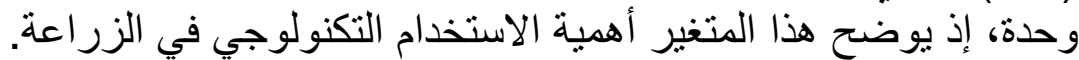

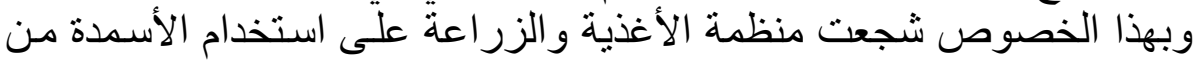

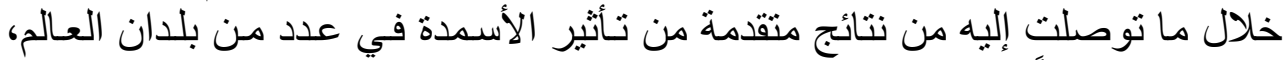

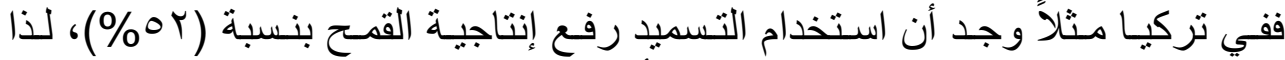

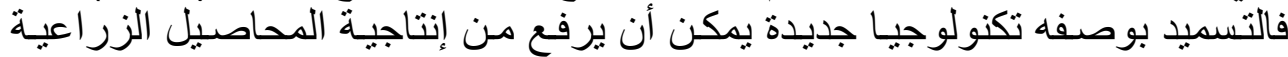

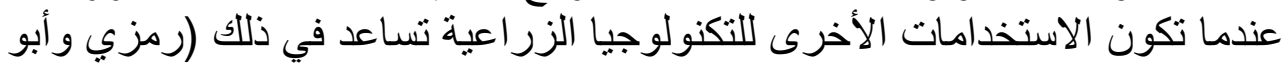

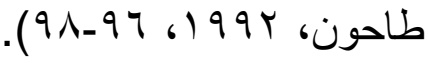




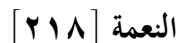

\section{r. الجمهورية العربية السورية}

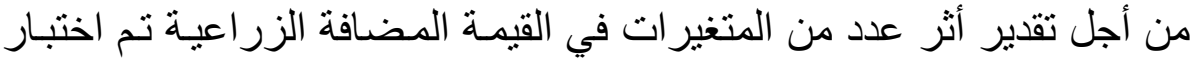

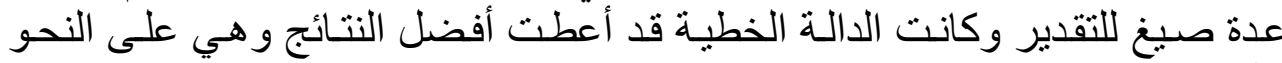
$Y=-19.3393+0.1303 X 1+0.2729 X 2-0.0179 X 3-7.1885 X 4+0.0312 X 5$
$\mathrm{t}^{*}$

$\mathrm{R}^{2}=74 \%$

$\mathrm{R}^{2}=67 \%$

$-\mathrm{F}=10.047 \%$

D.W $=2.47$

تشير القوة التفسيرية للأنموذج المقدر إلى أن VTV\% من التغيرات الحاصلة في

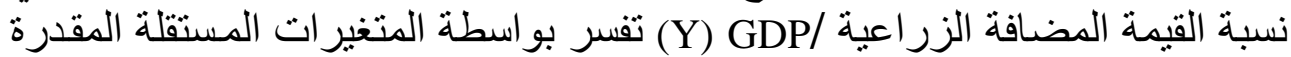

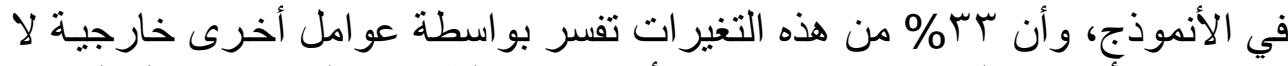

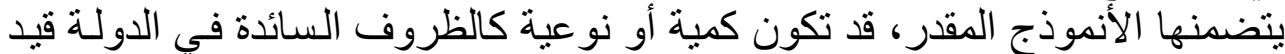

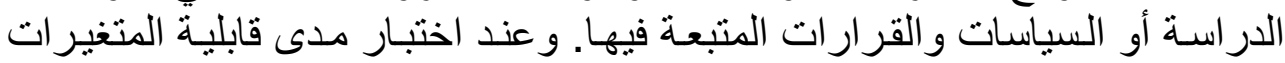

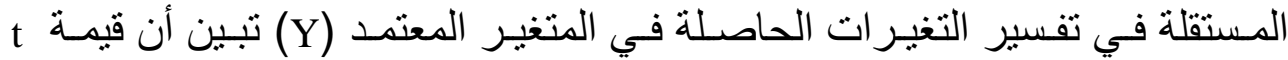

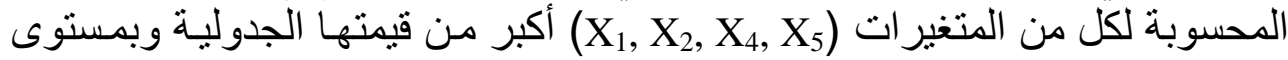
معنوية ٪\%، مما يدل على وجود علاقة سبيية بيذها وبين المتغير المعتمد.

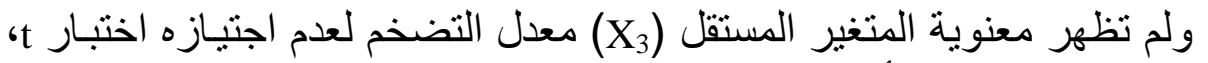

$$
\text { إذ كانت قيمة t المحسوبة أقل من قيمتها الجنة الجدولية. }
$$

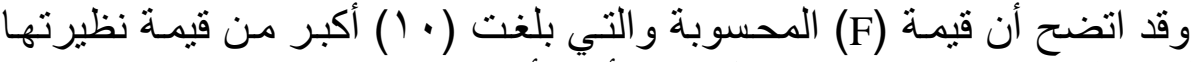

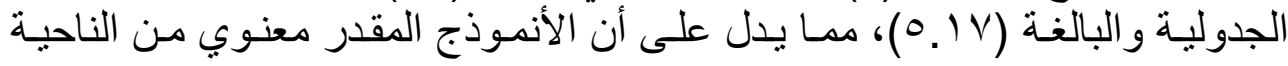
الإحصائية.

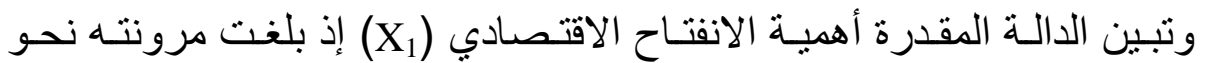

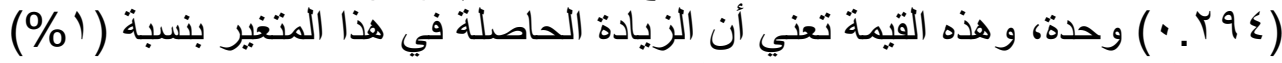

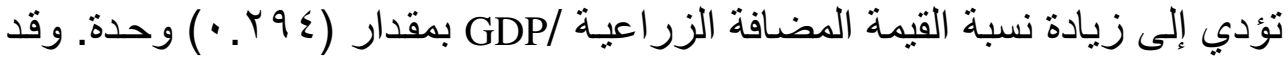

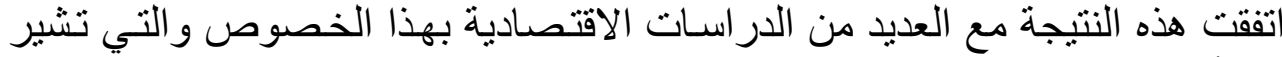

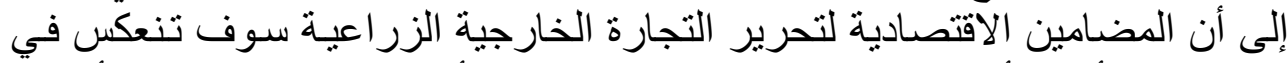

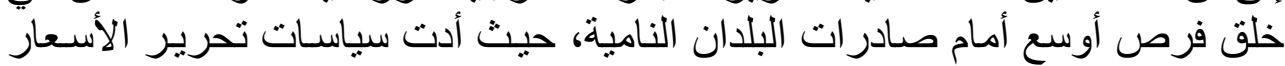

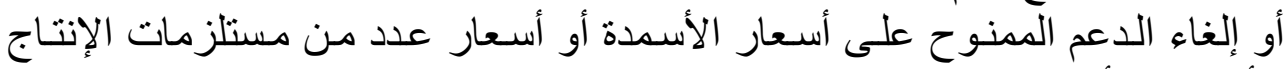

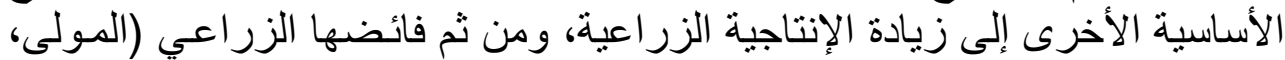

$$
\text { (1.0. (1.. }
$$

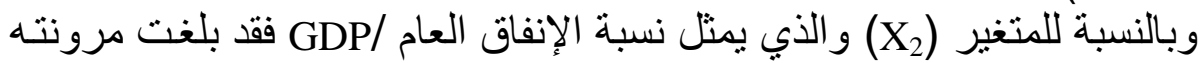

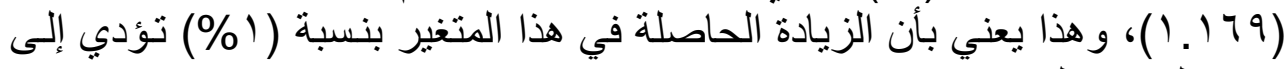

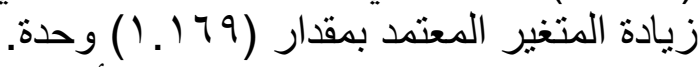

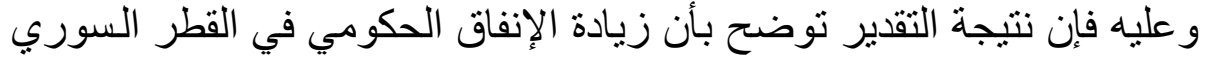

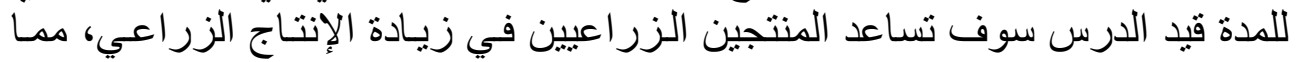
ينعكس ذلك في زيادة القيمة المضافة. 


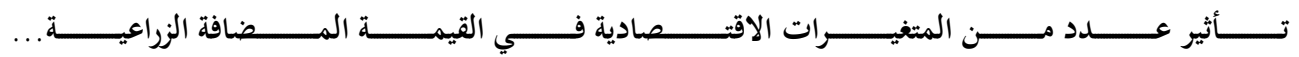

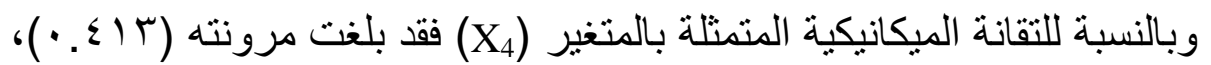

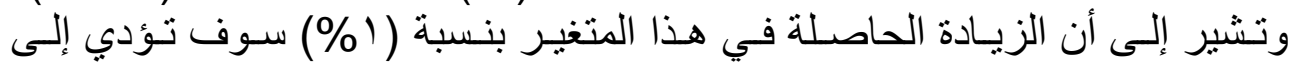

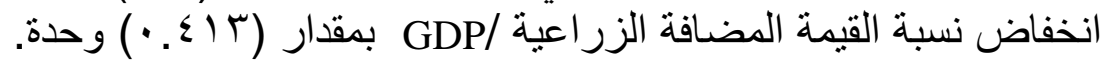

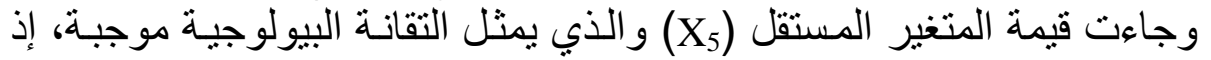

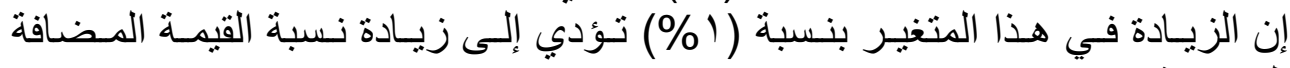

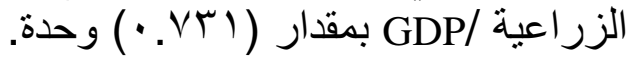

هن أجل تقدير أثر عدد من المتغير ات في القيمـة المضافة الزر اعية تم اختبار عدة صيغ للتقدير وكانت الدالة الخطية قد أعطت أفضل النتائج التي تتمنل في الأتي:

$$
\begin{array}{lcccc}
\mathrm{Y}=19.834 & -0.143 \mathrm{X} 1-0.003 \mathrm{X} 2 & -0.002 \mathrm{X} 3 & -0.008 \mathrm{X} 5 \\
\mathrm{t}^{*} & (3.7) & (0.07) & (0.11) \\
& - & &
\end{array}
$$

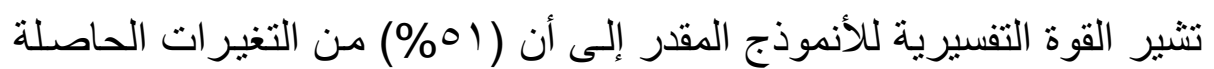

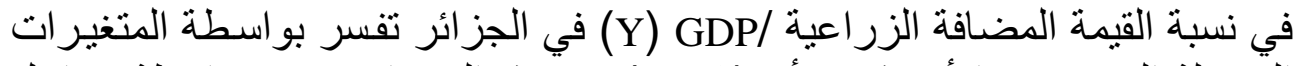

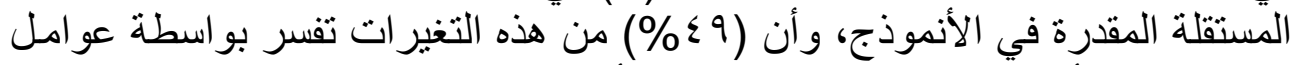

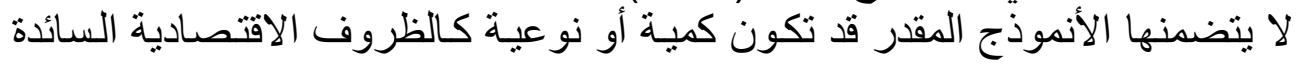

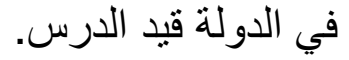

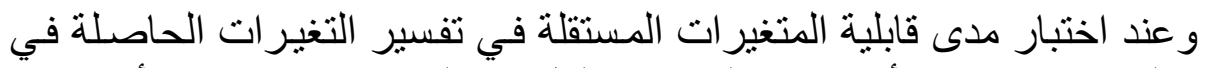

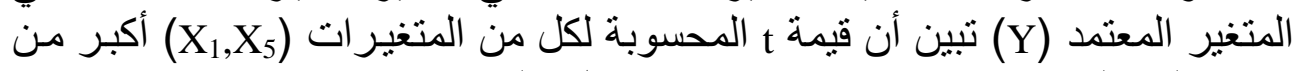

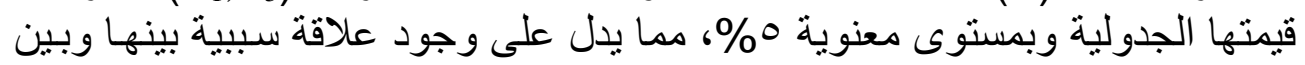

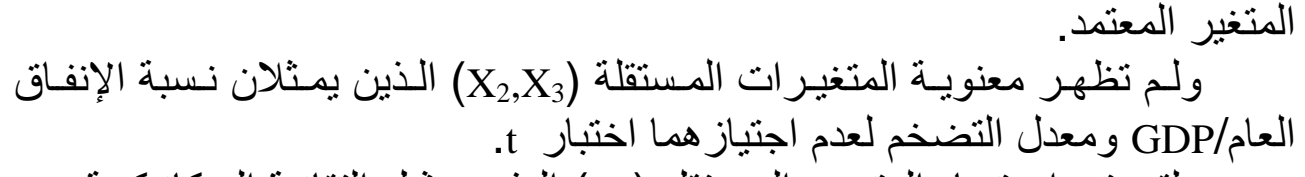

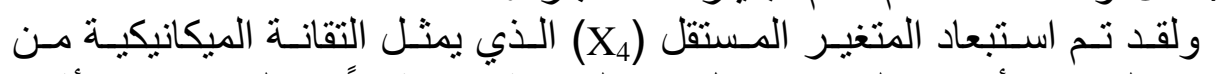

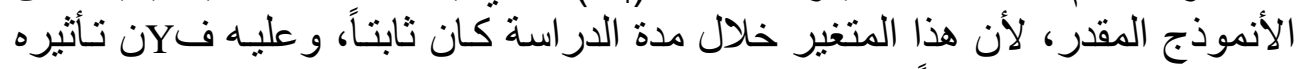

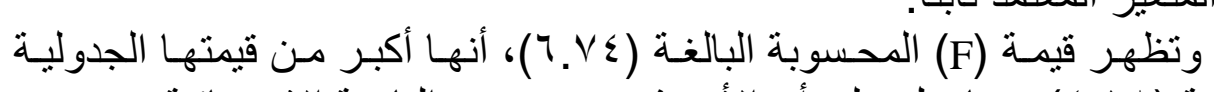

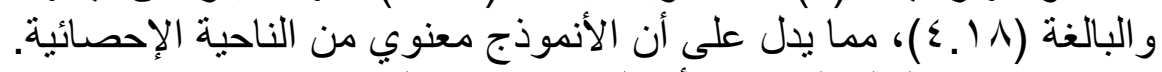

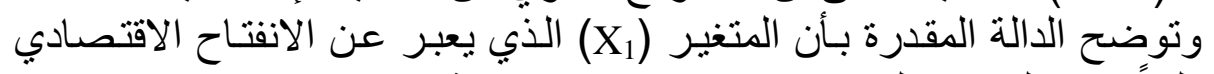

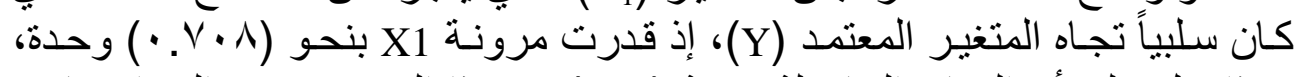

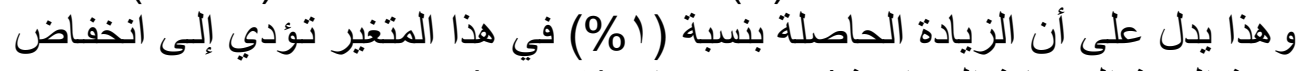

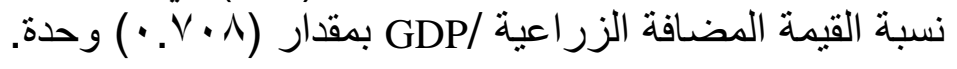




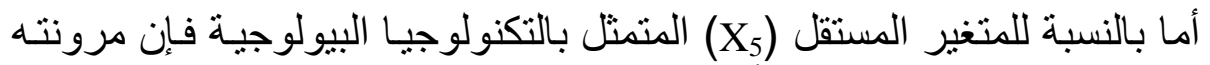

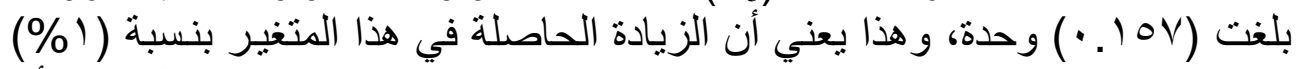

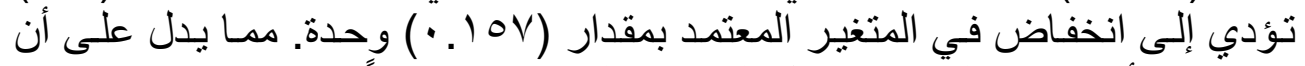

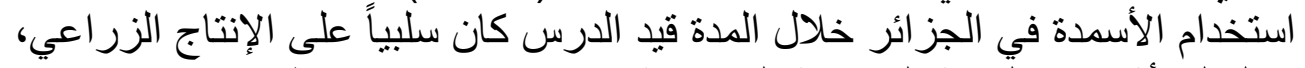

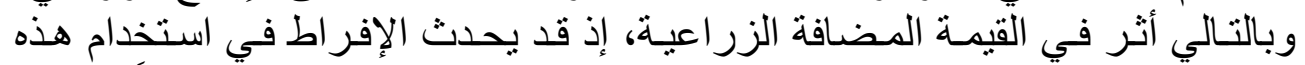

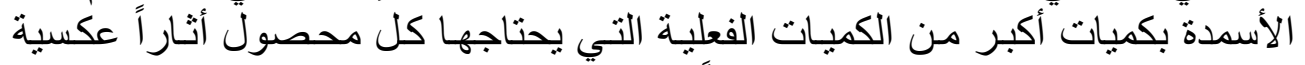
على الإنتاج الزراعي، مما ينعكس سلباً على القيمة المضافة الزئل الزراعية.

| - الاستنتاجات

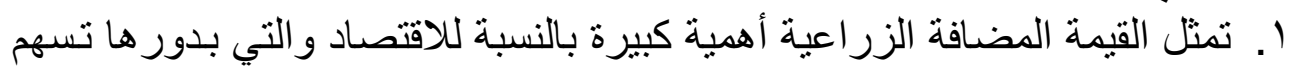

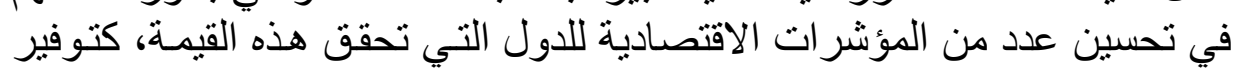

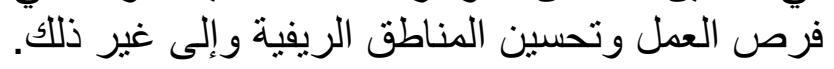

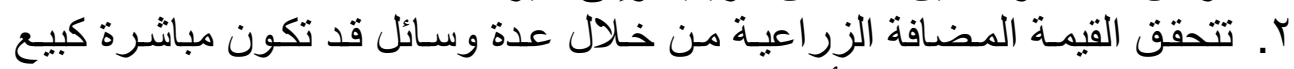

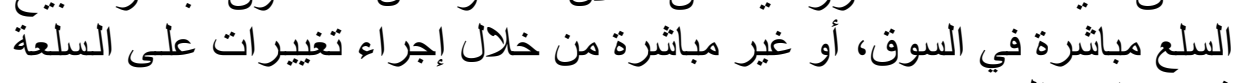

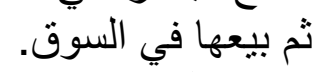

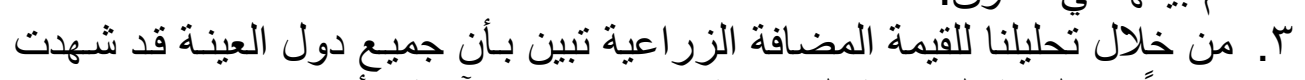

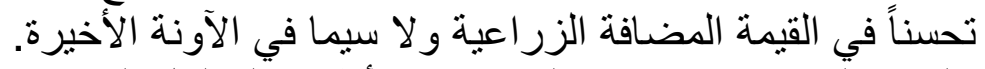

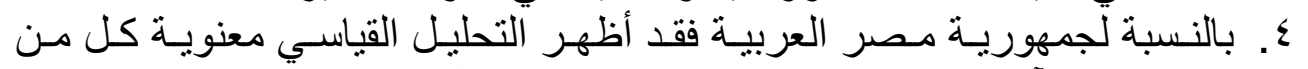

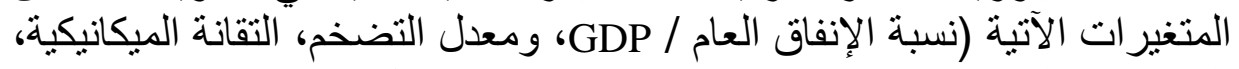

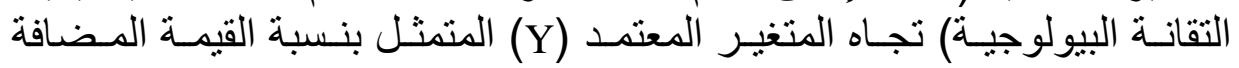

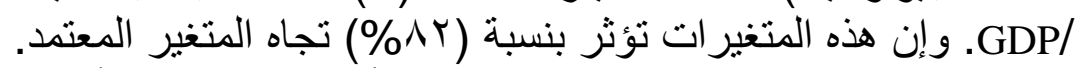

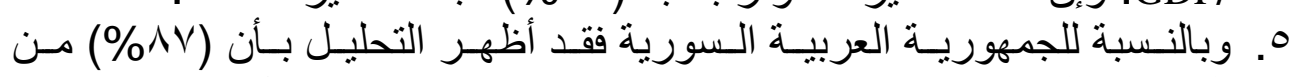

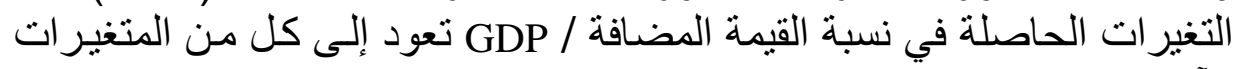

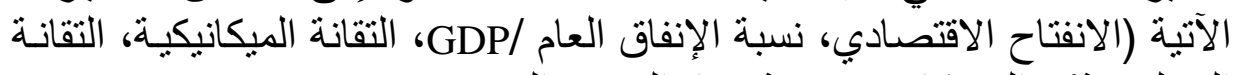

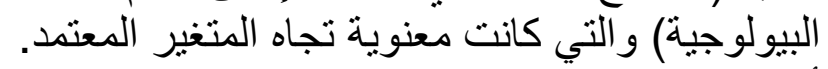

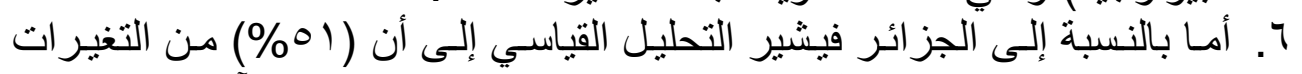

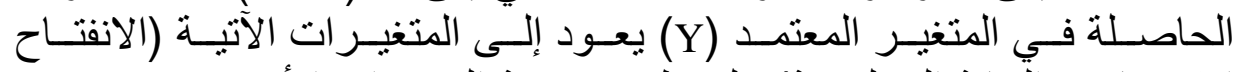

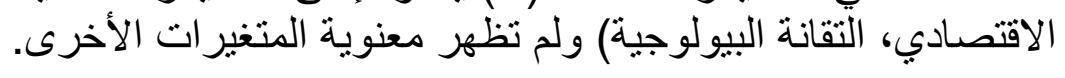

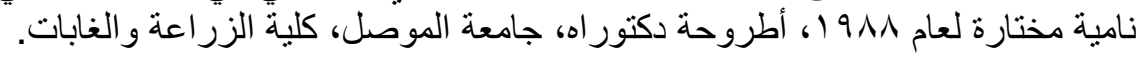




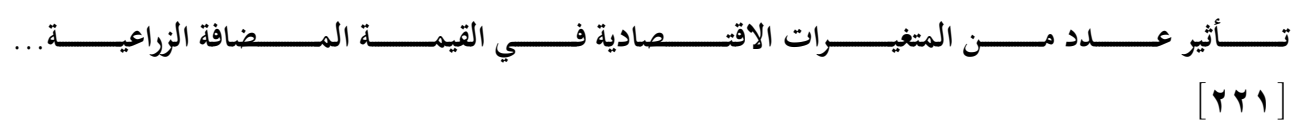

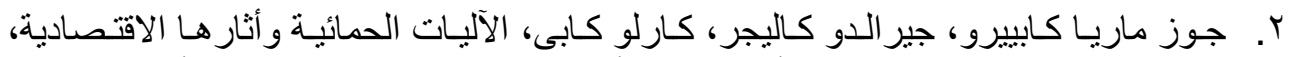

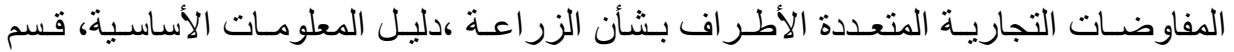

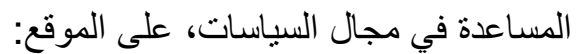

http://www.uae.gov.ae/uaeagricent/Issues/X7352a/X7352A03.htm

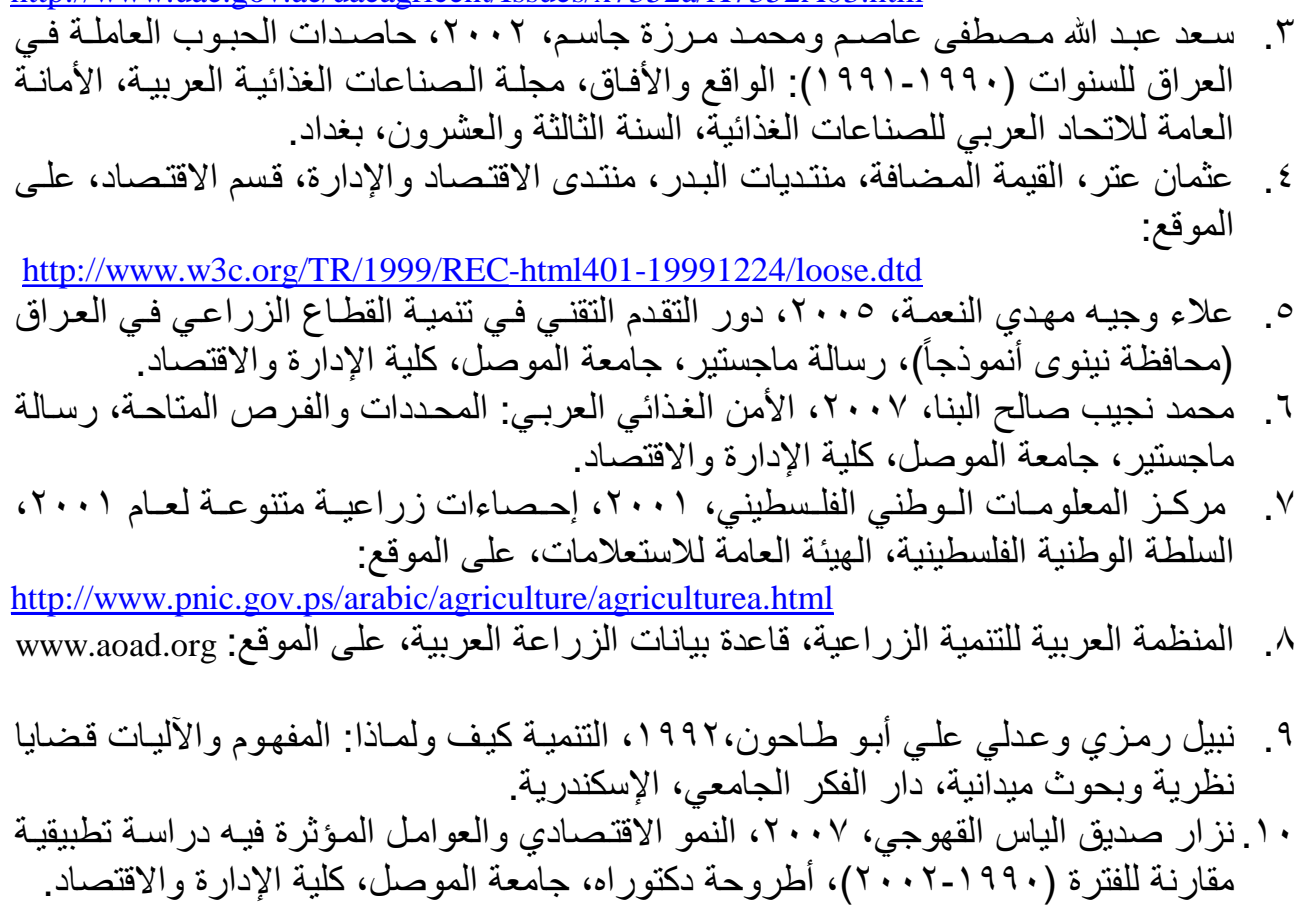

\section{ثانياً- المراجع باللغة الاجنبية}

1. David Coltrain, David Barton, AND Michael Boland, 2002, Value Added: Opportunities And Strategies, Department of Agricultural Economic, Cooperative Service, Kansas State University.

http://www.agecon.ksu.edu/accc/kcdc/PDF\%20Files/VALADD10\%202col.pdf

2. Kent Fleming, 2005, Value-Added Strategies: Taking Agricultural Products to the next Level, University of Hawaii at manoa, College of Tropical Agriculture and Human Resources, Department of Tropical Plant and Soil Sciences http://www.ctahr.hawaii.edu/oc/freepubs/pdf/AB-16.pdf

3. Tadlock Cowan, 2002, Value Added Agricultural Enterprises in Rural Development Strategies, Report for Congress, Visiting Scholar in Economic Growth and Entrepreneurship, Congressional Research Service, The Library Congress. http://bennelson.senate.gov/documents/CRS/Agriculture/CRSAddedValueEnterprises.pdf

4. Vincent Amanor- Boadu, A Conversation about Value-Added Agriculture. http://www.agecon.ksu.edu/accc/kcdc/PDF\%20Files/Value-Added\%20Concept.pdf

5. Worldbank, Statistics :www.worldbank.org 